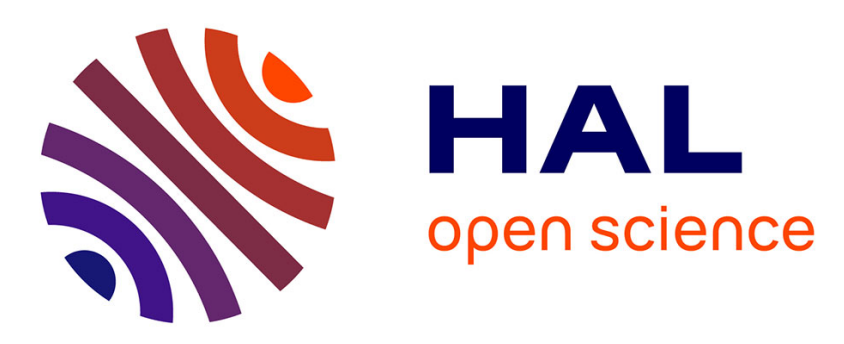

\title{
Molecular docking and pharmacogenomics of alkaloids and their monomeric precursors; vindoline and catharanthine
}

\author{
Serkan Sertel, Yujie Fu, Yuangang Zu, Blanka Rebacz, Badireenath \\ Konkimalla, Peter K. Plinkert, Alwin Krämer, Jürg Gertsch, Thomas Efferth
}

\section{To cite this version:}

Serkan Sertel, Yujie Fu, Yuangang Zu, Blanka Rebacz, Badireenath Konkimalla, et al.. Molecular docking and pharmacogenomics of alkaloids and their monomeric precursors; vindoline and catharanthine. Biochemical Pharmacology, 2011, 81 (6), pp.723. 10.1016/j.bcp.2010.12.026 . hal-00672298

\section{HAL Id: hal-00672298 \\ https://hal.science/hal-00672298}

Submitted on 21 Feb 2012

HAL is a multi-disciplinary open access archive for the deposit and dissemination of scientific research documents, whether they are published or not. The documents may come from teaching and research institutions in France or abroad, or from public or private research centers.
L'archive ouverte pluridisciplinaire HAL, est destinée au dépôt et à la diffusion de documents scientifiques de niveau recherche, publiés ou non, émanant des établissements d'enseignement et de recherche français ou étrangers, des laboratoires publics ou privés. 


\section{Accepted Manuscript}

Title: Molecular docking and pharmacogenomics of Vinca alkaloids and their monomeric precursors; vindoline and catharanthine

Authors: Serkan Sertel, Yujie Fu, Yuangang Zu, Blanka Rebacz, Badireenath Konkimalla, Peter K. Plinkert, Alwin

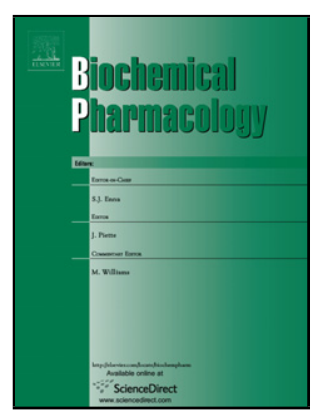

Krämer, Jürg Gertsch, Thomas Efferth

PII:

S0006-2952(11)00013-X

DOI: doi:10.1016/j.bcp.2010.12.026

Reference: BCP 10794

To appear in: $\quad B C P$

Received date: $\quad 17-11-2010$

Revised date: $\quad 23-12-2010$

Accepted date: $\quad$ 24-12-2010

Please cite this article as: Sertel S, Fu Y, Zu Y, Rebacz B, Konkimalla B, Plinkert PK, Krämer A, Gertsch J, Efferth T, Molecular docking and pharmacogenomics of Vinca alkaloids and their monomeric precursors; vindoline and catharanthine, Biochemical Pharmacology (2010), doi:10.1016/j.bcp.2010.12.026

This is a PDF file of an unedited manuscript that has been accepted for publication. As a service to our customers we are providing this early version of the manuscript. The manuscript will undergo copyediting, typesetting, and review of the resulting proof before it is published in its final form. Please note that during the production process errors may be discovered which could affect the content, and all legal disclaimers that apply to the journal pertain. 


\title{
Molecular docking and pharmacogenomics of Vinca alkaloids and their monomeric precursors, vindoline and catharanthine
}

Serkan Sertel $^{\mathbf{a}, \mathbf{e}, \mathbf{g}}$, Yujie Fu ${ }^{\mathbf{b}, \mathbf{c}}$, Yuangang Zu ${ }^{\mathbf{b}, \mathbf{c}}$, Blanka Rebacz ${ }^{\mathbf{d}}$, Badireenath Konkimalla ${ }^{\mathbf{e}}$, Peter K. Plinkert ${ }^{\mathbf{a}}$, Alwin Krämer ${ }^{\mathbf{d}}$, Jürg Gertsch ${ }^{\mathbf{e}}$ and Thomas Efferth ${ }^{\mathbf{e}, \mathbf{f}, \mathbf{g}, *}$

a Department of Otorhinolaryngology, Head and Neck Surgery, University of Heidelberg, Heidelberg, Germany

b Key Laboratory of Forest Plant Ecology, Ministry of Education, Northeast Forestry University, Harbin, China

${ }^{\mathbf{c}}$ Engineering Research Center of Forest Bio-Preparation, Ministry of Education, Northeast Forestry University, Harbin, China

d Clinical Cooperation Unit Molecular Hematology/Oncology, German Cancer Research Center and Department of Internal Medicine V, University of Heidelberg, Heidelberg, Germany

e Pharmaceutical Biology (C015), German Cancer Research Center, Heidelberg, Germany

${ }^{\mathrm{f}}$ Institute of Biochemistry and Molecular Medicine, University of Bern, Bern, Switzerland

${ }^{\mathrm{g}}$ Department of Pharmaceutical Biology, Institute of Pharmacy and Biochemistry, University of Mainz, Mainz, Germany

* Corresponding Author: Department of Pharmaceutical Biology, Institute of Pharmacy and Biochemistry, University of Mainz, Staudinger Weg 5, 55128 Mainz, Germany.

Phone: +49-6131-3925751; Fax: +49-6131-3923752; E-mail: efferth@uni-mainz.de

Running Title: Pharmacogenomics of Vinca Alkaloids

Keywords: centrosomal clustering, molecular docking, multidrug resistance, pharmacogenomics, vinca alkaloids

\begin{abstract}
Abbreviations: ABC transporter, ATP-binding cassette transporter; HNSCC, head and neck squamous cell carcinoma; $\mathrm{IC}_{50}, 50 \%$ inhibition concentration; RMSD, root mean square deviations; mRNA, messenger RNA; NCI, national cancer institute
\end{abstract}




\begin{abstract}
Vinblastine and vincristine are dimeric indole alkaloids derived from Catharanthus roseus (formerly: Vinca rosea). Their monomeric precursor molecules are vindoline and catharanthine. While vinblastine and vincristine are well-known mitotic spindle poisons, not much is known about vindoline and catharanthine. Vindoline and catharanthine showed weak cytotoxicity, while vinblastine, vincristine, and the semisynthetic vindesine and vinorelbine revealed high cytotoxicity towards cancer cells. This may reflect a general biological principle of poisonous plants. Highly toxic compounds are not only active towards predators, but also towards plant tissues. Hence, plants need mechanisms to protect themselves from their own poisons. One evolutionary strategy to solve this problem is to generate less toxic precursors, which are dimerized to toxic end products when needed. As shown by in silico molecular docking and biochemical approaches, vinblastine, vincristine and vinorelbine bound with high affinity to $\alpha / \beta$-tubulin and inhibited tubulin polymerization, whereas the effects of vindoline and catharanthine were weak. Similarly, vinblastine produced high fractions of mono- and multipolar mitotic spindles, while vindoline and catharanthine did only weakly affect bipolar mitotic spindle formation. Inhibition of centrosomal clustering represents a treatment novel strategy leading to multipolar spindle formation and apoptosis. This has been shown for vinblastine by us for the first time. P-glycoprotein-overexpressing multidrug-resistant CEM/VCR1000 cells were highly resistant towards vincristine and crossresistant to vinblastine, vindesine, and vinorelbine, but not or only weakly cross-resistant to vindoline and catharanthine. In addition to tubulin as primary target, microarray-based mRNA signatures of responsiveness of these compounds have been identified by COMPARE and signaling pathway profiling.
\end{abstract}




\section{Introduction}

Plants produce secondary metabolites as defense weapons against microbial infections by viruses, bacteria, or protozoa and parasites such as insects or worms as well as against herbivores. Many plants are poisonous, while others can serve as medicinal plants with pharmacological activity. As shown in a previous survey conducted by the National Cancer Institute (NCI), USA, more than two thirds of all anticancer drugs established in anticancer therapy are natural products, derivatives of natural products or mimic bioactive principles of natural products [1].

Among the clinically established natural products with anticancer activity are the Vinca alkaloids vinblastine and vincristine and more recently, the semi-synthetic derivatives vindesine and vinorelbine, which are highly useful drugs for the treatment of certain malignancies.

Vinca alkaloids arrest tumor cells during mitosis by binding to tubulin and depolymerization of microtubules [2]. This leads to cell cycle arrest in mitosis [3]. Besides interaction of Vinca alkaloids with tubulins, other mechanisms upstream (e.g. membranebound drug efflux transporters) and downstream (e.g. signal transduction pathways, programmed cell death) also account to the drugs' efficacy towards cancer cells.

Vinblastine and vincristine are dimeric indole alkaloids derived from Catharanthus roseus (formerly: Vinca rosea). Their monomeric precursor molecules are vindoline and catharanthine. While there is clear evidence for the action of vinblastine and vinblastine as mitotic spindle poisons, not much is known about the monomers vindoline and catharanthine.

Both precursor molecules are less cytotoxic than their dimeric drugs, vinblastine and vincristine. The question arises, whether this reflects a biological principle of poisonous plants. Poisonous natural products such as vinblastine and vincristine are effective defence mechanisms against herbivores and other predators. However, these compounds may also reveal toxicity to the plants themselves. Hence, they may generate and store large amounts of less toxic precursor molecules for self-protection, whereas the final synthesis of highly toxic end products occurs only upon appropriate external stimulation.

In the present investigation, we hypothesized that different cytotoxicities of monomeric precursors and dimeric end products should affect binding to the primary target of Vinca alkaloids, the microtubules. In addition, dimeric second-generation drugs, the semisynthetic vindesine and vinorelbine have been included in the study. A comparative analysis of functional effects of the above mentioned compounds on microtubule formation 
(effect on $\alpha / \beta$-tubulin polymerisation) has been carried out in vitro. The relative binding affinities of vindoline and catharanthine were estimated from Dixon plots assuming that all compounds either directly or indirectly (allosteric modulation) interfere with the $\left[{ }^{3} \mathrm{H}\right]$ vinblastine binding sites in $\alpha / \beta$-tubulin. The experimental data have been compared to molecular modelling studies. The binding of Vinca alkaloids to tubulin may not only cause inhibition of microtubule elongation, but may also affect mitotic spindle formation. The formation of multipolar mitotic spindles by inhibition of centrosomal coalescence has been anticipated as novel treatment strategy [4,5]. Therefore, we have analyzed the capacity of Vinca alkaoids to induce multipolar mitotic spindles. Finally, we have analyzed the role of drug resistance mechanisms for momomeric and dimeric Vinca alkaloids. We first analyzed cross-resistance of vincristine-resistant CEM/VCR1000 leukemia cells towards vindoline and catharanthine in comparison to vinblastine, vindesine, and vinorelbine. Then, we have analyzed other determinants of responsiveness towards Vinca alkaloids in the cell line panel of the NCI by means of COMPARE-analyses of microarray-based transcriptome-wide mRNA expression. 


\section{Material and Methods}

\subsection{Compounds}

Vindoline and cantharanthine were isolated from Cataranthus roseus as described [6]. Vinblastine sulphate, vincristine sulphate, vindesine sulphate salt, and vinorelbine ditartrate salt vindesine were obtained from Sigma-Aldrich (Taufkirchen, Germany). Vindoline and catharanthine are precursor molecules in the biosynthesis route, while vinblastine and vincristine are end products (Figure 1). The entire biosynthesis pathway has previously been elucidated [7]. Vindoline and catharanthine were isolated from Cataranthus roseus by two of the authors (YF and YZ). Vindesine and vinorelbine are semi-synthetic derivatives and were obtained from Sigma-Aldrich (Taufkirchen, Germany).

\subsection{Cell lines}

Human CCRF-CEM leukemia cells were maintained in RPMI medium (Gibco, Eggenstein, Germany) supplemented with $10 \%$ fetal calf serum in a humidified $7 \% \mathrm{CO}_{2}$ atmosphere at $37^{\circ} \mathrm{C}$. Cells were passaged twice weekly. All experiments were performed with cells in the logarithmic growth phase. The multidrug resistance gene 1 ( $A B C B 1, M D R 1)$-expressing CEM/VCR1000 subline was maintained in $1000 \mathrm{ng} / \mathrm{mL}$ vincristine. The establishment of the resistant subline has been described [8]. Sensitive and resistant cells were kindly provided by Dr. A. Sauerbrey (Dept. of Pediatrics, University of Jena, Jena, Germany).

The HNSCC cell line SCC114 (oral squamous cell carcinoma) cells were cultured in Dulbecco's modified Eagle's Medium (DMEM, Gibco, Invitrogen, Karlsruhe, Germany) supplemented with $10 \%$ FCS (Biochrom AG, Berlin, Germany). When indicated, vindoline, catharanthine, or vinblastine were added to the cell culture medium for $24 \mathrm{~h}$. In all experiments, the final DMSO concentration was $<1 \%$.

The panel of 60 human tumor cell lines of the Developmental Therapeutics Program of the NCI consisted of leukemia, melanoma, non-small cell lung cancer, colon cancer, renal cancer, and ovarian cancer cells, cells of tumors of the central nervous system, prostate carcinoma, and breast cancer. Their origin and processing have been previously described [9]. 


\subsection{Sulforhodamine B assay}

The determination of drug sensitivity in the NCI cell lines by the sulforhodamine B assay has been reported [10]. The $50 \%$ inhibition concentration $\left(\mathrm{IC}_{50}\right)$ values for vinblastine, vincristine, catharanthine, and vindoline have been deposited in the database of the database of the Developmental Therapeutics Program of the NCI (http://dtp.nci.nih.gov).

\subsection{Growth inhibition assay}

The in vitro response to drugs was evaluated by means of a growth inhibition assay as described [10]. Aliquots of $5 \times 10^{4}$ cells $/ \mathrm{ml}$ were seeded in 24-well plates and compounds were immediately added at different drug concentrations to allow calculation of $50 \%$ inhibition concentration $\left(\mathrm{IC}_{50}\right)$ values. Cells were counted seven days after drug treatment. The resulting growth data represent the net outcome of cell proliferation and cell death.

\subsection{Preparation of pure $\alpha / \beta$-tubulin $(>95 \%)$}

Tubulin was isolated as pure $\alpha / \beta$-tubulin from fresh pig brain according to a previously described method [11]. Fresh brains were obtained from the local slaughterhouse and processed immediately without prior cooling. In brief, 150-200 g cleaned pig brain was put into ice-cooled depolymerization buffer (50 mM MES, $1 \mathrm{mM} \mathrm{CaCl}_{2}$, adjusted to pH 6.9 with $\mathrm{KOH})$ and homogenized in a Polytron mixer. The homogenate was centrifuged in a Sorvall SLA-1500 rotor at $14,500 \mathrm{rpm}$ for $60 \mathrm{~min}$. The supernatant was transferred into an Erlenmeyer flask in high-molar PIPES-buffer (1 M PIPES, $10 \mathrm{mM} \mathrm{MgCl} 2,20 \mathrm{mM}$ EGTA adjusted to pH 6.9 with $\mathrm{KOH}$ ) plus ATP (1.5 mM final concentration) and glycerol (98\%) ad $300 \mathrm{~mL}$. The resulting suspension was mixed and incubated at $37^{\circ} \mathrm{C}$ for $1 \mathrm{~h}$. Aliquots were transferred into ultracentrifuge tubes and centrifuged in a Beckman Ti50.2 rotor at 32,500 $\mathrm{rpm}(96,000 \times \mathrm{g})$ for $75 \mathrm{~min}$ at $30^{\circ} \mathrm{C}$. The microtubule protein pellets were suspended in depolymerization buffer and put on ice prior to ultracentrifugation at $4{ }^{\circ} \mathrm{C}$. The procedure was repeated for two polymerization cycles (total of three cycles) and the final $\alpha / \beta$-tubulin pellets were suspended in ice-cold Brinkley Buffer (BRB80; $80 \mathrm{mM}$ PIPES, $1 \mathrm{mM} \mathrm{MgCl}_{2}, 1 \mathrm{mM}$ 
EGTA adjusted to $\mathrm{pH} 6.8$ with $\mathrm{KOH}$ ) prior to shock-freezing in liquid nitrogen and subsequent storage at $-80^{\circ} \mathrm{C}$. Purity and concentration of $\alpha / \beta$-tubulin were determined by SDS-PAGE gel electrophoresis and spectrophotometrically $(A=\varepsilon . c . d$ with a given extinction coefficient of $115,000 \mathrm{M}^{-1} \mathrm{~cm}^{-1}$ ) at $280 \mathrm{~nm}$. This procedure typically yielded 60$100 \mathrm{mg}$ of $\alpha / \beta$-tubulin per $100 \mathrm{~g}$ of brain.

\subsection{Radioligand displacement $\alpha / \beta$-tubulin}

Tubulin in BRB80 buffer $(0.5 \mathrm{~mL}, 5-10 \mu \mathrm{M})$ was incubated with two different concentrations of $\left[\mathrm{G}-{ }^{3} \mathrm{H}\right]$-vinblastine (American Radiolabeled Chemicals, Inc.) $(5$ and $10 \mu \mathrm{M})$ on ice for 30 min. Different concentrations of unlabeled vindoline, catharanthine, vincristine, vindesine, or vinorelbine were added and the mixture was incubated at $37^{\circ} \mathrm{C}$ for $30 \mathrm{~min}$. DMSO was used as vehicle control. Bound radioactivity was separated by gel filtration on a Sephadex G50 column on micro columns and measured in a scintillation counter.

\subsection{Turbidimetry analysis of polymer formation}

Freshly thawed $\alpha / \beta$-tubulin was centrifuged at $5,000 \times \mathrm{g}$ for $5 \mathrm{~min}$ at $5^{\circ} \mathrm{C}$ and then incubated with additional BRB80 buffer, drugs, DMSO vehicle, GTP/glutamate $(25 \mathrm{mM} / 2.7 \mathrm{M})$ and/or MAPs, respectively, in a 96-well plate in either 50 or $100 \mu \mathrm{L}$ volumes. Experiments were either carried out in a 96-well quartz plate or in normal 96-well polystyrene plates (Falcon). The polymerization was monitored real-time at $340 \mathrm{~nm}$ in a temperature-controlled TECAN GeniosPro spectrophotometer. Depending on the specific experiment, the temperature was set either to RT (actual measuring temperature was $24-27^{\circ} \mathrm{C}$ ) or $37^{\circ} \mathrm{C}$. The concentration of DMSO was found to be highly critical, because concentrations $>2 \%$ DMSO induced considerable MT formation. UV absorption of compounds was subtracted from absorption curves. All experiments, along with both negative (untreated $\alpha / \beta$-tubulin) and vehicle controls, were carried out in triplicate. Experiments were performed at least with two different $\alpha / \beta$-tubulin batches. 


\subsection{Immunofluorescence}

Cells grown on cover slips were fixed in $-20^{\circ} \mathrm{C}$ methanol/acetone (1:1) for 7 min and then blocked in $10 \%$ goat serum/PBS. The primary mouse monoclonal antibody to $\mathrm{Eg} 5$ (Transduction Laboratories, Lexington, KY) was incubated for $1 \mathrm{~h}$ following $30 \mathrm{~min}$ incubation with a fluorochrome-conjugated secondary antibody anti-mouse Cy3 (Jackson ImmunoResearch Laboratories, West Grove, PN). Immunostained cells were examined using a Zeiss Axiovert $200 \mathrm{M}$ fluorescence microscope (Göttingen, Germany) and images were processed with Photoshop software (Adobe, Munich, Germany).

Kinesin-related motor protein Eg5 (also known as kinesin-like protein KIF11, kinesin-like spindle protein HKSP) is localized at the centrosomes, spindle microtubules, and intracellular bridge. Eg5 is required for establishing the bipolar spindle.

\subsection{Molecular docking of Vinca alkaloids on tubulin}

The x-ray structure of tubulin-colchicines-vinblastine: stahmnin-like domain complex (SLD) was used as docking template throughout the docking calculations. The coordinates of vinblastine were extracted from the PDB file, obtained from the Brookhaven Protein Data Bank (PDB 1Z2B) [12]. Docking calculations were performed using AutoDock program (AutoDock 4.2, The Scripps Research Institute, La Jolla, CA, USA) installed on a Linux PC under the SuSe operating system. AutoDock is an automated and robust docking algorithm based on the Lamarckian genetic algorithm (GA) with several success rates in the virtual screening of ligands.

The 2D structures of vincristine, vinblastine, vinorelbine, videsine, cantharanthine and vindoline were energy-minimised and converted to 3D structures compatible for docking operation using an open source program PRODRG [13].

Prior to start of the docking operation, essential hydrogens and Gasteiger chargers were added to the macromolecule. In order to sample the binding site, a grid of $60 \AA \times 60 \AA \times$ $60 \AA$ with a spacing of $0.375 \AA$ was first computed. In total, 100 cycles of flexible ligand docking were performed in the grid representation of the receptor binding site, followed by scoring the ligand-receptor interaction. AutoDock clustering was performed based on similarities in binding modes and affinities in these cycles. The optimized orientations represent possible binding modes of the ligand within the site. The AutoDock docking output 
contains solutions ranked according to the scoring functions with information about the frequency of occurrence, mean energies, inhibition constant and low root mean square deviations (RMSD) within the cluster each defined by the 3D coordinates. PyMOL (Schrödinger, Portland, OR, USA) was used as visualization tool to further get a deeper insight on the binding modes obtained from docking [14].

\subsection{Statistical analyses}

The mRNA expression values of 60 cell lines of the genes of interest were selected from the NCI database (http://dtp.nci.nih.gov). The mRNA expression has been determined by microarray analyses $[15,16]$. COMPARE analyses were performed to produce rank-ordered lists of genes expressed in the NCI cell line panel. The methodology has been described previously in detail [17]. Briefly, every gene of the NCI microarray database is ranked for similarity of its mRNA expression to the $\mathrm{IC}_{50}$ values for Vinca alkaloids. To derive COMPARE rankings, a scale index of correlations coefficients (R-values) is created. In the standard COMPARE approach, greater mRNA expression in cell lines correlates with enhanced drug resistance, whereas in reverse COMPARE analyses, greater mRNA expression in cell lines indicates drug sensitivity.

The Ingenuity Pathway Analysis software (IPA) (Ingenuity Systems, Mountain View, CA, USA; http://www.ingenuity.com) was utilized to identify networks and pathways of interacting genes and other functional groups in genomic data. Using the IPA Functional Analysis tool, we were able to associate biological functions and diseases to the experimental results. Moreover, we used a biomarker filter tool and the Network Explorer for visualizing molecular relationships.

For hierarchical cluster analysis, objects were classified by calculation of distances according to the closeness of between-individual distances. All objects were assembled into a cluster tree (dendrogram). The merging of objects with similar features leads to the formation of a cluster, where the length of the branch indicates the degree of relation. The distance of a subordinate cluster to a superior cluster represents a criterion for the closeness of clusters as well as for the affiliation of single objects to clusters. Thus, objects with tightly related features appear together, while separation in the cluster tree increases with progressive dissimilarity. Recently, cluster models have been validated for gene expression profiling and for approaching molecular pharmacology of cancer $[15,18]$. Cluster analyses applying the WARD method were done with the WinSTAT program (Kalmia, Cambridge, MA, USA)). 
Missing values were automatically omitted by the program, and the closeness of two joined objects was calculated by the number of data points they contained. In order to calculate distances between all variables included in the analysis, the program automatically standardizes the variables by transforming the data with a mean $=0$ and a variance $=1$.

Pearson's correlation test was used to calculate significance values and rank correlation coefficients as a relative measure for the linear dependency of two variables. This test was implemented into the WinSTAT Program.. Pearson's correlation test determines the correlation of rank position of values. Ordinal or metric scaling of data is suited for the test and data are transformed into rank positions. There is no condition regarding normal distribution of the data set for the performance of Pearson's correlation test. 


\section{Results}

\subsection{Cytotoxicity}

The NCI cell line panel has been tested for sensitivity towards vinblastine, vincristine, catharanthine, or vindoline. The mean $\log _{10} \mathrm{IC}_{50}$ values of eight different tumor types for these compounds are shown in Figure 2. Cell lines of all tumor types revealed high cytotoxicity with mean $\log _{10} \mathrm{IC}_{50}$ values for vinblastine in a range of $-9.26 \pm 0.04 \mathrm{M}$ (leukemia) to $-8.15 \pm$ $0.41 \mathrm{M}$ (ovarian carcinoma) and for vincristine in a range of $-6.95 \pm 0.01 \mathrm{M}$ (leukemia) to $6.14 \pm 0.49 \mathrm{M}$ (breast cancer). Catharanthine and vindoline displayed only weak activity.

\subsection{Inhibition of tubulin polymerization by Vinca alkaloids}

Vincristine potently inhibited microtubule assembly and catharanthine showed a less potent effect on $\alpha / \beta$-tubulin polymerization (Figure 3). Vindoline was not able to reach considerable inhibition of microtubule assembly, suggesting that this compound does not or only very weakly interact with $\alpha / \beta$-tubulin. In addition, we analyzed the semi-synthetic derivatives, vindesine and vinorelbine. Both drugs inhibited microtubule assembly in a comparable manner as vincristine (Figure 3).

\subsection{Uncompetitive inhibition of the binding $\left[{ }^{3} \mathrm{H}\right]$ vinblastine to tubulin by catharanthine}

In competition experiments, catharanthine clearly interfered with $\left[{ }^{3} \mathrm{H}\right]$-vinblastine for $\alpha / \beta$ tubulin binding in an apparently uncompetitive manner (Figure 4). Uncompetitive inhibition takes place, when a tubulin ligand (here catharanthine) binds only to the complex formed between tubulin and vinblastine (the T-V complex).

\subsection{Molecular docking}

The x-ray structure of vinblastine bound to tubulin in a complex with the RB3 protein stathmin-like domain was selected as a docking template (PDB 1Z2B) [19]. The template and 
the docking parameters, using AutoDock, were validated by docking the crystallographic structure of vinblastine into the binding site of the protein template. Docking results showed low RMSD values between the experimental and the calculated docked structure and set a good platform to reliably dock other structurally similar chemical molecules. Vinca alkaloids were individually docked into the validated grid defined in the crystal structure of $\alpha / \beta$-tubulin for appropriate conformational search. Next, 100 cycles of docking with approximately 250,000 energy evaluations in each cycle were carried out without any flexibility constraints on the ligand. The results were finally analyzed upon setting identical conditions for docking the tubulin structure template with vincristine, vinblastine, vinorelbine, vindesine, catharanthine and vindoline chemical molecules throughout the operation (Figure 5).

The final docking results show that vindesine, vincristine, vinorelbine and vinblastine posses a high-order in the frequency of occurrence in a cluster and closeness in parameters in terms of mean docking energy $(-8.52,-8.50,-8.47$ and $-8.37 \mathrm{kcal} / \mathrm{mol}$ respectively) and predicted inhibition constant $(1.49,2.05,1.54,1.67 \mu \mathrm{M})$ as shown in Table I. In contrast, vindoline and catharanthine showed relatively low mean docking energies (-7.28 and -7.0 $\mathrm{kcal} / \mathrm{mol}$, respectively) and inhibition constants (4.72 and $7.34 \mu \mathrm{M}$, respectively) (Table I), which implies a low affinity to tubulin binding.

The ligand-protein interaction was analyzed using the LPC tool [20]. Binding site analysis showed that interaction of Vinca alkaloids (except of catharanthine) with Asn249C was a conserved feature (Table II). Interaction of Val177B was observed for four of the six Vinca alkaloids analyzed and interaction of Pro175B with three compounds (Table II). No Hbond interaction of catharanthine to any amino acid in the pharmacophore was found. The four clinically established Vinca alkaloids revealed 12-15 residues involved in hydrophobic interaction with the ligand, whereas vindoline and catharanthine exerted hydrophobic interaction with only 9 residues each. 


\subsection{Induction of mono- and multipolar mitoses}

To analyze whether vinblastine and its precursors, vindoline and catharanthine, exert a part of their poisonous effects by induction of multipolar mitotic spindles, SCC114 cells were treated for $24 \mathrm{~h}$ with each of the three compounds and immunostained with an anti-Eg5 monoclonal antibody to visualize mitotic figures. Counterstaining of DNA was done using DAPI. As shown in Figure 6A, untreated SCC114 cells contained 6.6\% monopolar, 85\% bipolar, and $8.3 \%$ multipolar mitoses. Treatment with $100-300 \mathrm{nM}$ vindoline led to a dose-dependent increase of monopolar mitoses up to $23.5 \%$. At higher concentrations, the fraction of monopolar mitoses decreased. At doses of 250-500 nM vindoline, a weak increase of multipolar mitoses was recorded (12-15\%). Above $500 \mathrm{nM}$ vindoline, general cytotoxicity precluded further analysis of mitotic spindles in SCC114 cells. According to the increase of mono- or multipolar mitoses, the fraction of bipolar mitoses dose-dependently decreased in a range between 100 and $500 \mathrm{nM}$.

Catharanthine showed a different effect on spindle polarity than vindoline. As shown in Figure 6B, there was a strong increase of monopolar mitoses up to $37.5 \%$ and no increase of multipolar mitoses upon treatment with 150-210 nM catharanthine. Accordingly, the percentages of bipolar mitoses dose-dependently decreased from $84 \%$ (control) to $50 \%$ (210 $\mathrm{nM}$ ). At higher concentrations, catharanthine was cytotoxic. Vinblastine induced a considerable percentage particularly of multipolar mitoses (Figure 6C). Representative examples of multipolar mitoses in SCC114 cells treated with vindoline, catharanthine, or vinblastine and bipolar mitoses in untreated control cells are depicted in Figure 7.

\subsection{Multidrug resistance}

Since the activity of Vinca alkaloids may not only be determined by binding to tubulin as primary target, but also by mechanisms upstream of this target, we investigated the role of the multidrug resistance-conferring drug transporter, P-glycoprotein. We treated drug-sensitive, parental CCRF-CEM leukemia cells and vincristine-resistant CEM/VCR1000 cells with catharanthine, vindoline, and four clinically established Vinca alkaloids. Calculation of the degrees of resistance from the $\mathrm{IC}_{50}$ values revealed that vincristine was one order and vinblastine two orders of magnitude more cytotoxic towards CCRF-CEM cells than catharanthine or vindoline (Table III), while vindesine was about two-fold less active than 
vincristine, vinorelbine was two orders of magnitude more active than vincristine. CEM/VCR1000 cells were 41.8-fold resistant towards vincristine as compared to the parental CCRF-CEM cell line. Interestingly, CEM/VCR1000 cells showed higher degrees of resistance (56.2- to 341.9-fold, respectively) towards vinblastine, vindesine, or vinorelbine than the resistance-selecting agent, vincristine itself. Degrees of resistance towards catharanthine or vindoline were only low ( 2-fold) (Table III).

\subsection{Cross-resistance}

To further analyze determinants of resistance and sensitivity towards Vinca alkaloids, we took advantage of the database of the Developmental Therapeutics Program of NCI, USA. We first analyzed the cross-resistance profile of the NCI tumor cell panel to Vinca alkaloids. There was a highly significant correlation between the $\log _{10} \mathrm{IC}_{50}$ values for vinblastine and vincristine $\left(\mathrm{R}=0.789 ; P=6.5 \times 10^{-16}\right)$, whereas vincristine cytotoxicity did not correlate with catharanthine or vindoline activity (Table IV). The $\log _{10} \mathrm{IC}_{50}$ values for catharanthine were significantly associated with those for vindoline $(P=0.01)$, but at a low $\mathrm{R}$-value (0.310). Other relationships were not found.

\subsection{COMPARE analyses of microarray data}

Next, we performed COMPARE analyses of the $\mathrm{IC}_{50}$ values for vinblastine, vincristine, vindoline, and catharanthine and the transcriptome-wide mRNA expression of the NCI cell lines to produce scale indices of correlation coefficients. We first performed a standard COMPARE analysis in which cell lines that were most inhibited by Vinca alkaloids (lowest $\mathrm{IC}_{50}$ values) were correlated with the highest mRNA expression levels of genes. Genes with correlation coefficients of $\mathrm{R}>0.5$ are shown in Table $\mathbf{V}$. If more than 10 genes met this criterion, only the top 10 genes for each compound are listed. If more than one clone of the same gene appeared in the COMPARE ranking lists, only the clone with the best R-value was displayed. These genes may be considered as possible candidate genes, which determine cellular resistance to Vinca alkaloids. Afterwards, reverse COMPARE analyses were done $(\mathrm{R}<-0.5)$, which correlated the most inhibited cell lines with the lowest gene expression levels (Table V). This approach provided genes that are associated with cellular sensitivity to Vinca alkaloids. A comparison showed that no genes appeared in association with more than one of 
the compounds, indicating that different genes may determine cellular response to these compounds.

\subsection{Hierarchical cluster analyses}

The genes obtained by standard and reverse COMPARE analyses for vindoline, catharanthine, vinblastine and vincristine were subjected to hierarchical cluster analysis to obtain a dendrogram, where the cell lines are arranged according to their expression profile of these genes. The dendrogram for each of the Vinca alkaloids investigated can be divided into three major cluster branches (Figure 8). Then, the median $\log _{10} \mathrm{IC}_{50}$ values for Vinca alkaloids were used as cut-off threshold to define cell lines as being sensitive or resistant. As can be seen in Table VI, the distribution of sensitive or resistant cell lines was significantly different between the branches of the dendrograms for catharanthine or vindoline, indicating that cellular response to these two Vinca alkaloids was predictable by these genes. Statistical significant results were not obtained for vinblastine or vincristine, indicating that the genes identified by microarray and COMPARE analyses did not predict cellular response to these two drugs.

\subsection{Ingenuity Pathway Analyses}

As a next step, we employed signaling route analyses. The genes identified by microarray and COMPARE analyses were subjected to Ingenuity Pathway Analysis software (version 6.5). Several groups of biological functions for genes were found to be significant in that they contained more of the identified genes than expected by chance. The genes determining sensitivity or resistance to catharanthine belonged to groups with the following biological functions: cell-to-cell signaling and interaction, developmental disorder, genetic disorder, and hematological system and development and function and other groups (Figure 9A). The most important groups of genes determining cellular response to vindoline were drug metabolism, molecular transport, small molecule biochemistry and genetic disorder (Figure 9B). Since the genes identified by COMPARE analyses did not significantly predict sensitivity and resistance to vinblastine or vincristine (Table VI), signaling pathway analyses were not applied for these two drugs. 


\section{Discussion}

In the present investigation, we analyzed the cytotoxic potential of vindoline and catharanthine, two precursors of the mitotic spindle poisons, vinblastine and vinblastine. In addition to these natural products, the semi-synthetic derivatives, vindesine and vinorelbine of the second-generation have been investigated.

A striking feature was that the monomeric precursors, vindoline and catharanthine, were less cytotoxic towards cancer cells than the dimeric drugs, vinblastine and vincristine. This may reflect a general biological principle of poisonous plants. Highly toxic compounds are not only active towards predators, but also towards plant tissues. Hence, plants need mechanisms to protect themselves from their own poisons. One evolutionary strategy to solve this problem is to generate less toxic precursors, which are dimerized to toxic end products when needed. Storage of large amounts of the less toxic precursors, vindoline and catharanthine, is possible without harm for plants. Upon appropriate stimulation, high amounts of the toxic compounds vinblastine and vincristine can rapidly be synthesized by the plants. This hypothesis is supported by the fact that radical oxygen species foster the biosynthesis of vinblastine and vinblastine from its precursors, vindoline and catharanthine [7]. Exposure of periwinkle plants with $\mathrm{H}_{2} \mathrm{O}_{2}$ induced dimerization of the precursors to vinblastine [21]. Translating this experimental data to real life situations could mean that leaves attacked by plant-eating herbivores may be exposed to higher amounts of oxygen and radical oxygen species, which act as stimulus to defend the plant against the herbivore by vinblastine and vincristine production.

Microtubules are crucial for chromosomal segregation during mitosis. Clinically established Vinca alkaloids act as mitotic spindle poisons by inhibition of tubulin polymerization. Many cancer cells contain supernumerary centrosomes, which may contribute to aneuploidy induction via multipolar mitotic spindle formation. However, since spindle multipolarity is antagonistic to cell viability, tumor cells have developed centrosomal clustering mechanisms to prevent multipolar spindle formation by coalescence of multiple centrosomes into two functional spindle poles [5, 22]. Inhibition of centrosome clustering represents a novel strategy for cancer drug development and leads to the formation of multipolar spindles with subsequent apoptosis induction. SCC114 is an oral squamous carcinoma cell line characteristic for the phenotype of centrosomal clustering [4]. Even though the majority of the cell population harbours supernumerary centrosomes, only a few mitotic cells form multipolar spindles. The residual cell population coalesces their 
centrosomes into two spindle poles, thus, being able to divide in a bipolar manner. In the present investigation, treatment with vinblastine induced the formation of multipolar spindles in SCC114 cells in a considerable fraction of mitoses. In contrast, treatment with much higher concentrations of both, catharanthine or vindoline, only led to very few cells showing spindle multipolarity. This indicates vinblastine may in part trigger cell death, similar to other drugs that interfere with tubulin polymerization like griseofulvin, by induction of spindle multipolarity [4]. Importantly, the capacity for multipolar spindle induction of the drugs analyzed clearly correlated with the cytotoxicity of the compounds, i.e. the highly cytotoxic vinblastine better induced multipolar spindle formation than the weakly cytotoxic vindoline or catharanthine. Another interesting finding was that, in contrast to vinblastine, vindoline and catharantine perferentially induced monopolar spindles, which may be related to different functions of both monomers in the vinblastine dimer.

It has previously been reported that the vindoline moiety is necessary for anchoring, while the catharanthine moiety confers cytotoxicity [23]. This view is conceivable with our molecular docking data showing that the weakly cytotoxic vindoline shares the residue Asn249C as binding partner for vinblastine, vincristine, vindesine, and vinorelbine, whereas the intermediate cytotoxic catharanthine did not bind to any amino acid at all. This may also contribute to differential effects on the formation of mono- and multipolar mitotic spindles.

Remarkably, the less cytotoxic precursors were also less cross-resistant in multidrugresistant CEM/VCR1000 cells (2-fold versus 40-to 340-fold). Because they are less toxic, there is no need for cancer cells to extrude them out of the cell by P-glycoprotein. It is unknown why the resistance of the selecting agent, vinblastine in CEM/VCR1000 is less than the cross-resistance towards non-selecting Vinca alkaloids (vincristine, vindesine, vinorelbine). ATP-binding cassette (ABC) transporters are not only relevant for multidrug resistance of tumor cells, but are also widely distributed in microbiology as detoxification mechanisms for xenobiotics. From an evolutionary point of view, there is less need to extrude less toxic compounds out of cells than toxic ones. ABC transporters are part of the Phase I-III system of enzymes and transporters in mammals to cope with xenobiotic compounds taken up with nutrition.

Interestingly, a high degree of cross-resistance was observed between vinblastine and vincristine, but between the precursors, vindolidine and catharanthine, and vinblastine or vincristine. This may indicate similar modes of action of vinblastine and vincristine, but not of vindoline and catharanthine. This assumption drawn from correlation analyses was substantiated by measurement of microtubule formation. The weakly active vindoline did not 
inhibit tubulin polymerization and the moderately cytotoxic catharanthine inhibited tubulin polymerization only at higher concentrations as compared to the highly cytotoxic drugs vinblastine, vincristine, and vinorelbine. This result underlines the importance of tubulin as primary target of Vinca alkaloids in cancer therapy. Vinblastine, vincristine, vindesine and vinorelbine revealed a considerably higher binding affinity to the Vinca pharmacophore on tubulin as their precursors, vindoline or catharanthine. A closer inspection of amino acids in the binding region showed that all compounds except catharanthine attached to the residue Asn249C. In addition to Asn249C, each compound, except catharanthine showed H-bond interactions to variable other amino acids. Whereas vinblastine, vincristine, and vinblastine bound to 5-7 amino acids in our in silico docking approach, vindoline bound to only four residues and catharanthine did not show considerable interaction with amino acids in the pharmacophore. Similarly, the number of hydrophobic interactions of the clinically established Vinca alkaloids was higher than that of vindoline or catharanthine. This speaks for weaker interactions of vindoline and catharanthine with tubulin than of the other drugs, which nicely compares to the results on inhibition of tubulin polymerization in our biochemical assay.

In addition to binding to tubulin as primary target and P-glycoprotein as upstream mechanism of drug resistance, other molecular determinants for cellular response towards Vinca alkaloids may also be taken into account. Therefore, we performed COMPARE analyses of microarray-based transcriptome-wide mRNA expression profiling. It was of interest that the mRNA expression different genes (or still not assigned coding regions) correlated with sensitivity or resistance to catharanthine or vindoline, but not to vinblastine or vincristine. This may indicate that tubulin as common target may be of utmost importance for the highly cytotoxic vinblastine and vincristine. The weakly cytotoxic catharanthine and vindoline, which also only weakly bind to tubulin may have other determinants of response of tumor cells. Therefore, the hierarchical clustering were statstistically significant for catharanthine or vindoline, but not for vinblastine or vincristine.

The only gene which appeared in reverse COMPARE analyses of both vinblastine and vincristine was claudin 1 (CLDN1). Claudins are proteins constituting tight junctions at the blood brain barrier. It has been reported that components of tight junctions confer resistance to vinblastine [24]. Hence, the role of claudin 1 for cellular response towards Vinca alkaloids merits further investigation in the future.

In conclusion, we found that the monomers, vindoline and catharanthine, showed weak cytotoxicity, respectively, while dimeric vinblastine, vincristine, vindesine, and 
vinorelbine revealed high cytotoxicity towards cancer cells. As shown by in silico molecular docking approaches and biochemical experiments in vitro, vinblastine, vincristine and vinorelbine bound with high affinity to $\alpha / \beta$-tubulin and inhibited tubulin polymerization, whereas the effects of vindoline and catharanthine were weak. Similarly, vinblastine produced high rates of multipolar mitotic spindles, while vindoline and catharanthine did only weakly affect bipolar mitotic spindle formation. P-glycoprotein-overexpressing multidrug-resistant CEM/VCR1000 cells were highly resistant towards vincristine and cross-resistant to vinblastine, vindesine, and vinorelbine, but not or only weakly cross-resistant to vindoline and catharanthine. In addition to tubulin as primary target, microarray-based mRNA signatures of responsiveness of these compounds have been identified by COMPARE and signaling pathway profiling.

\section{Conflict of interest}

There is no conflict of interest. 


\section{Legends}

Figure 1: Chemical structures of Vinca alkaloids.

Figure 2: $\log _{10} \mathrm{IC}_{50}$ values for Vinca alkaloids. Mean values \pm SEM of 60 cell lines were grouped according to their tumor origin.

Figure 3: Inhibition of tubulin polymerization by Vinca alkaloids. Purified $\alpha / \beta$-tubulin $(25 \mu \mathrm{M})$ was polymerized at $37^{\circ} \mathrm{C}$ in BRB80 assembly buffer with $\mathrm{GTP} /$ glutamate $(25 \mathrm{mM} / 2.7 \mathrm{M})$ and with increasing concentrations of test compounds $(\mu \mathrm{M})$. Turbidity was measured at $340 \mathrm{~nm}$ after $45 \mathrm{~min}$. Endpoints $\left(\Delta_{340}\right)$ mean values are plotted as a non-linear function of drug concentration \pm SEM $(\mathrm{N}=3)$.

Figure 4: Dixon plot, uncompetitive inhibition of the binding $\left[{ }^{3} \mathrm{H}\right]$ vinblastine to tubulin by catharanthine. $\left[{ }^{3} \mathrm{H}\right]$ vinblastine at $5 \mu \mathrm{M}$ (black circles) and $10 \mu \mathrm{M}$ (white circles) was incubated with purified $\alpha / \beta$-tubulin $(10 \mu \mathrm{M})$ and catharanthine $(0.5-5 \mu \mathrm{M})$. After centrifugal gel filtration on a Sephadex G50 column the bound $\left[{ }^{3} \mathrm{H}\right]$-vinblastine was measured by scintillation counting. Data points are mean values of three experiments. Dotted line shows putative $K_{\mathrm{i}}$ value.

Figure 5: Molecular docking studies of Vinca alkaloids. Docking of (A) six Vinca alkaloids into a specific common $\alpha / \beta$ pharmacophore, (B) catharanthine, (C) vindoline, (D) vinblastine, $(\mathrm{E})$ vincristine, $(\mathrm{F})$ vindesine, and $(\mathrm{G})$ vinoelbine.

Figure 6: Induction of mono- and multipolar mitoses and decrease of bipolar mitoses after treatment of SCC114 cells for $24 \mathrm{~h}$ with (A) vindoline, (B) catharanthine, or (C) vinblastine as determined by immunofluorescence.

Figure 7: Representative immunofluorescence images of bipolar mitoses of untreated SCC114 cells (upper panel) and of multipolar mitoses of SCC114 cells treated with vinblastine (second panel), catharanthine (third panel), or vindoline (lower panel) for $24 \mathrm{~h}$. 
Figure 8: Dendrograms of hierarchical cluster analysis obtained from mRNA expression of genes correlating with $\log _{10} \mathrm{IC}_{50}$ values for (A) catharanthine, (B) vindoline, (C) vinblastine, and (D) vincristine. The dendrograms show the clustering of the NCI cell lines.

Figure 9: Assignment of biological functions of gene products associated with cellular response towards catharanthine and vindoline. Genes identified by COMPARE analyses (Table V) were subjected to Ingenuity pathway analysis software. Top 10 biological functions of genes associated with response to (A) catharanthine and (B) vindoline. 
Table I: Molecular docking of Vinca alkaloids to $\alpha / \beta$-tubulin dimer.

Table II: Interaction of Vinca alkaloids at the Vinca pharmacophore of the $\alpha / \beta$-tubulin dimer.

Table III: Resistance profile of multidrug-resistant human CEM/VCR1000 leukemia cells to Vinca alkaloids.

Table IV: Correlation of $\log _{10} \mathrm{IC}_{50}$ values for Vinca alkaloids of the NCI cell line panel. * $P$-values, Pearson correlation test.

Table V: Genes identified by standard or reverse COMPARE analyses whose mRNA expression in the NCI cell line panel correlated with $\mathrm{IC}_{50}$ values for Vinca alkaloids.

Table VI: Separation of clusters of the NCI cell line panel obtained by hierarchical cluster analysis shown in Figure 8 in comparison to Vinca alkaloids. The $\log _{10} \mathrm{IC}_{50}$ median values (M) of each compound were used as cut-off values to define cell lines as being sensitive or resistant. N.S., not significant $(P>0.05)$. 


\section{References}

[1] Cragg GM, Grothaus PG, Newman DJ. Impact of natural products on developing new anti-cancer agents. Chem Rev 2009;109:3012-43.

[2] Okouneva T, Hill BT, Wilson L, Jordan MA. The effects of vinflunine, vinorelbine, and vinblastine on centromere dynamics. Mol Cancer Ther 2003;2:427-36.

[3] Gidding CE, Kellie SJ, Kamps WA, de Graaf SS. Vincristine revisited. Crit Rev Oncol Hematol 1999;29:267-87.

[4] Rebacz B, Larsen TO, Clausen MH, Ronnest MH, Loffler H, Ho AD, Kramer A. Identification of griseofulvin as an inhibitor of centrosomal clustering in a phenotype-based screen. Cancer Res 2007;67:6342-50.

[5] Leber B, Maier B, Fuchs F, Chi J, Riffel P, Anderhub S, Wagner L, Ho AD, Salisbury JL, Boutros M, Kramer A. Proteins required for centrosome clustering in cancer cells. Sci Transl Med 2010;2:33ra38.

[6] Zhang L, Yang L, Niu H, Zu Y. Separation of vindoline,catharanthine and vinblastine from catharanthus roseus (1.) g.Don with macroporous adsorption resin. J Chem Industry Engineering (China) 2008;59:607-14.

[7] El-Sayed M, Verpoorte R. Catharanthus terpenoid indole alkaloids: Biosynthesis and regulation. Phytochem Rev 2007;6:277-305.

[8] Kimmig A, Gekeler V, Neumann M, Frese G, Handgretinger R, Kardos G, Diddens H, Niethammer D. Susceptibility of multidrug-resistant human leukemia cell lines to human interleukin 2-activated killer cells. Cancer Res 1990;50:6793-9.

[9] Alley MC, Scudiero DA, Monks A, Hursey ML, Czerwinski MJ, Fine DL, Abbott BJ, Mayo JG, Shoemaker RH, Boyd MR. Feasibility of drug screening with panels of human tumor cell lines using a microculture tetrazolium assay. Cancer Res 1988;48:589-601.

[10] Rubinstein LV, Shoemaker RH, Paull KD, Simon RM, Tosini S, Skehan P, Scudiero DA, Monks A, Boyd MR. Comparison of in vitro anticancer-drug-screening data generated with a tetrazolium assay versus a protein assay against a diverse panel of human tumor cell lines. $\mathbf{J}$ Natl Cancer Inst 1990;82:1113-8.

[11] Castoldi M, Popova AV. Purification of brain tubulin through two cycles of polymerization-depolymerization in a high-molarity buffer. Protein Expres Purif 2003;32:8388.

[12] Berman HM, Westbrook J, Feng Z, Gilliland G, Bhat TN, Weissig H, Shindyalov IN, Bourne PE. The protein data bank. Nucleic Acids Res 2000;28:235-42.

[13] Schuttelkopf AW, van Aalten DM. Prodrg: A tool for high-throughput crystallography of protein-ligand complexes. Acta Crystallogr D Biol Crystallogr 2004;60:1355-63.

[14] DeLano WL. The pymol molecular graphics system. DeLano Scientific. San Carlos, CA, USA, 2002.

[15] Scherf U, Ross DT, Waltham M, Smith LH, Lee JK, Tanabe L, Kohn KW, Reinhold WC, Myers TG, Andrews DT, Scudiero DA, Eisen MB, Sausville EA, Pommier Y, Botstein $\mathrm{D}$, Brown PO, Weinstein JN. A gene expression database for the molecular pharmacology of cancer. Nat Genet 2000;24:236-44.

[16] Amundson SA, Do KT, Vinikoor LC, Lee RA, Koch-Paiz CA, Ahn J, Reimers M, Chen Y, Scudiero DA, Weinstein JN, Trent JM, Bittner ML, Meltzer PS, Fornace AJ, Jr. Integrating global gene expression and radiation survival parameters across the 60 cell lines of the national cancer institute anticancer drug screen. Cancer Res 2008;68:415-24.

[17] Wosikowski K, Schuurhuis D, Johnson K, Paull KD, Myers TG, Weinstein JN, Bates SE. Identification of epidermal growth factor receptor and c-erbb2 pathway inhibitors by correlation with gene expression patterns. J Natl Cancer Inst 1997;89:1505-15. 
[18] Efferth T, Fabry U, Osieka R. Apoptosis and resistance to daunorubicin in human leukemic cells. Leukemia 1997;11:1180-6.

[19] Gigant B, Wang C, Ravelli RB, Roussi F, Steinmetz MO, Curmi PA, Sobel A, Knossow M. Structural basis for the regulation of tubulin by vinblastine. Nature 2005;435:519-22.

[20] Sobolev V, Sorokine A, Prilusky J, Abola EE, Edelman M. Automated analysis of interatomic contacts in proteins. Bioinformatics 1999;15:327-32.

[21] Tang Z, Yang L, Zu Y, Guo X. Variations of vinblastine accumulation and redox state affected by exogenous h2o2 in catharanthus roseus (1.) g. Don. Plant Growth Regul 2009;57:15-20.

[22] Quintyne NJ, Reing JE, Hoffelder DR, Gollin SM, Saunders WS. Spindle multipolarity is prevented by centrosomal clustering. Science 2005;307:127-9.

[23] Prakash V, Timasheff SN. Mechanism of interaction of vinca alkaloids with tubulin: Catharanthine and vindoline. Biochemistry 1991;30:873-80.

[24] Cohen-Kashi Malina K, Cooper I, Teichberg VI. Closing the gap between the in-vivo and in-vitro blood-brain barrier tightness. Brain Res 2009;1284:12-21. 


\section{Professor S.J. Enna \\ Editor-in-Chief of "Biochemical \\ Pharmacology"}

via: online submission system

\section{Manuscript submission}

Dear Prof. Enna,

Enclosed, please, find a manuscript entitled: "Molecular docking and pharmacogenomics of Vinca alkaloids and their monomeric precursors, vindoline and catharanthine."

Vinblastine and vincristine are dimeric indole alkaloids derived from Catharanthus roseus. Their monomeric precursor molecules are vindoline and catharanthine. While there is clear evidence for the action of vinblastine and vinblastine as mitotic spindle poisons, not much is known about the monomers vindoline and catharanthine. Both precursor molecules are less cytotoxic than their dimeric drugs, vinblastine and vincristine. In the present investigation, we hypothesized that different cytotoxicities of monomeric precursors and dimeric end products should affect binding to the primary target of Vinca alkaloids, the microtubules. A comparative analysis of functional effects of the above mentioned compounds on microtubule formation (effect on $\alpha \beta$-tubulin polymerisation) has been carried out in vitro. The relative binding affinities of vindoline and catharanthine were estimated from Dixon plots assuming that all compounds either directly or indirectly (allosteric modulation) interfere with the $\left[{ }^{3} \mathrm{H}\right]$-vinblastine binding sites in $\alpha \beta$-tubulin. The experimental data have been compared to molecular modelling in silico studies and microarray-based cluster analyses.

The formation of multipolar mitotic spindles by inhibition of centrosomal coalescence has been anticipated as novel treatment strategy. Inhibition of centrosomal clustering represents a novel strategy for cancer drug development and leads to the formation of multipolar spindles with subsequent apoptosis induction. Contribution to cell death by interference with spindle polarity has been shown for vinblastine by us for the first time.

In light of these results, we would be pleased, if you find this manuscript worth publishing in "Biochemical Pharmacology".

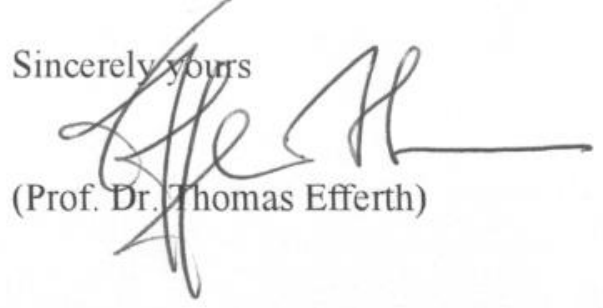

Fachbereich Chemie, Pharmazie und Geowissenschaften

Institut für Pharmazie und Biochemie

Prof. Dr. Thomas Efferth Abteilungsleiter

Johannes Gutenberg-

Universität Mainz

Staudinger Weg 5

D-55099 Mainz

Tel. $+49(0) 6131-3925751$ Fax +49(0)6131-3923752

efferth@uni-mainz.de

www pharmazie unimainz de/akefferth.htm

Info-Bereich 1

Datum 17.11.2010

Ihre Zeichen/Nachricht

Unsere Zeichen/Nachricht

Sekretariat

Info-Bereich 2

Verteiler

Anlage

Zweit-Adresse

Vertretungen 
Table I: Molecular docking of Vinca alkaloids to $\alpha / \beta$-tubulin dimer.

$\begin{array}{lcc}\text { Compound } & \begin{array}{c}\text { Mean Docking energy } \\ \text { (kcal/mol) }\end{array} & \begin{array}{c}\text { Mean pKi value } \\ (\boldsymbol{\mu M})\end{array} \\ \text { Vindesine } & -8.52 & 1.49 \\ \text { Vincristine } & -8.50 & 2.05 \\ \text { Vinorelbine } & -8.47 & 1.54 \\ \text { Vinblastine } & -8.37 & 1.67 \\ \text { Vindoline } & -7.28 & 4.72 \\ \text { Catharanthine } & -7.00 & 7.34\end{array}$

${ }^{*}$ pKi, predicted inhibitory constant 
Table II: Interaction of Vinca alkaloids at the Vinca pharmacophore of the $\alpha / \beta$-tubulin dimer.

\begin{tabular}{|l|l|c|}
\hline & \multicolumn{1}{|c|}{} & $\begin{array}{c}\text { No ridues involved in } \\
\text { Residues involved in H-Bond interaction with ligand } \\
\text { hydrophobic interactions } \\
\text { with the ligand }\end{array}$ \\
\hline Vinblastine & $\begin{array}{l}\text { ASN249C; LYS176B; PRO175B; SER178B; TYR210B; } \\
\text { VAL177B; VAL353C }\end{array}$ & 13 \\
\hline Vincristine & $\begin{array}{l}\text { ASN249C; ASN329C; LYS336C; PRO222B; TYR210B; } \\
\text { VAL177B }\end{array}$ & 15 \\
\hline Vindesine & ASN249C; ASN329C; PRO175B; VAL177B; VAL353C & 12 \\
\hline Vinorelbine & ASN329C; PRO175B; PRO222B; VAL353C & 13 \\
\hline Vindoline & ASN249C; ASN329C; PRO222B; VAL177B & 9 \\
\hline Catharanthine & none & 9 \\
\hline
\end{tabular}


Table III: Resistance profile of multidrug-resistant human CEM/VCR1000 leukemia cells to Vinca alkaloids.

\begin{tabular}{cccc} 
& $\begin{array}{c}\text { CCRF-CEM } \\
\left(M e a n \mathrm{IC}_{50} \pm \mathrm{SD},\right. \\
\mu \mathrm{M})\end{array}$ & $\begin{array}{c}\text { CEM/VCR1000 } \\
\left(\mathrm{Mean} \mathrm{IC}_{50} \pm \mathrm{SD},\right. \\
\mu \mathrm{M})\end{array}$ & $\begin{array}{c}\text { Degree of } \\
\text { Resistance }\end{array}$ \\
\hline Catharanthine & $13.7 \pm 4.5$ & $29.8 \pm 1.22$ & 2.2 \\
Vindoline & $14.0 \pm 6.28$ & $24.1 \pm 3.67$ & 1.7 \\
Vincristine & $1.92 \pm 0.14$ & $80.2 \pm 10.2$ & 41.8 \\
Vinblastine & $0.468 \pm 0.06$ & $26.3 \pm 1.6$ & 56.2 \\
Vindesine & $2.93 \pm 0.02$ & $229 \pm 24.4$ & 78.2 \\
Vinorelbine & $0.031 \pm 0.006$ & $10.6 \pm 0.89$ & 341.9
\end{tabular}


Table IV: Correlation of $\log _{10} \mathrm{IC}_{50}$ values for Vinca alkaloids of the NCI cell line panel.

${ }^{*} P$-values, Pearson correlation test

\begin{tabular}{lllll} 
& & Vindoline & Vinblastine & Vincristine \\
\hline Catharanthine & R-Value & 0.311 & 0.015 & -0.015 \\
& P-Value & 0.010 & 0.455 & 0.455 \\
Vindoline & R-Value & & -0.088 & 0.078 \\
& P-Value & & 0.261 & 0.283 \\
Vinblastine & R-Value & & & 0.789 \\
& P-Value & & & $6.518 \times 10^{-16}$
\end{tabular}


Table V: Genes identified by standard or reverse COMPARE analyses whose mRNA expression in the NCI cell line panel correlated with $\mathrm{IC}_{50}$ values for Vinca alkaloids.

\begin{tabular}{|c|c|c|c|c|c|}
\hline $\begin{array}{l}\text { COMPARE } \\
\text { Coefficient }\end{array}$ & $\begin{array}{l}\text { Gene } \\
\text { Symbol }\end{array}$ & $\begin{array}{l}\text { GeneBank } \\
\text { Acc. No. }\end{array}$ & Pattern ID & Gene Name & Gene Function \\
\hline \multicolumn{6}{|c|}{$\begin{array}{l}\text { Catharanthine: } \\
\text { Standard } \\
\text { COMPARE }\end{array}$} \\
\hline 0.591 & FLNB & AF042166 & GC55768 & $\begin{array}{l}\text { filamin B, beta } \\
\text { (actin binding protein } \\
\text { 278) }\end{array}$ & $\begin{array}{l}\text { filamin family member; links transmembrane } \\
\text { proteins } \\
\text { with actin cytoskeleton; repair of vascular injuries }\end{array}$ \\
\hline 0.554 & NFE2L3 & NM_004289 & GC183078 & $\begin{array}{l}\text { Rho-guanine nucleotide } \\
\text { exchange factor }\end{array}$ & $\begin{array}{l}\text { leucine zipper transcription factor family member; } \\
\text { involved in antioxidant response }\end{array}$ \\
\hline 0.55 & null & AA455079 & GC148639 & unknown & unknown \\
\hline $\begin{array}{l}0.548 \\
0.546 \\
0.545 \\
0.543\end{array}$ & $\begin{array}{l}\text { null } \\
P O D X L \\
\text { null } \\
\text { null }\end{array}$ & $\begin{array}{l}\text { Al940225 } \\
\text { U97519 } \\
\text { AA010617 } \\
\text { NM } 022448\end{array}$ & $\begin{array}{l}\text { GC79478 } \\
\text { GC30864 } \\
\text { GC39732 } \\
\text { GC189007 }\end{array}$ & $\begin{array}{l}\text { unknown } \\
\text { podocalyxin-like } \\
\text { unknown } \\
\text { 7 unknown }\end{array}$ & $\begin{array}{l}\text { unknown } \\
\text { anti-adhesin } \\
\text { unknown } \\
\text { unknown }\end{array}$ \\
\hline \multicolumn{6}{|l|}{$\begin{array}{l}\text { Catharanthin } \\
\text { e: Reverse } \\
\text { COMPARE }\end{array}$} \\
\hline-0.625 & DLGAP2 & Al221403 & GC61102 & $\begin{array}{l}\text { discs, large (Drosophila) } \\
\text { homolog-associated } \\
\text { protein } 2\end{array}$ & $\begin{array}{l}\text { membrane-associated guanylate kinase; } \\
\text { neuronal cell signaling }\end{array}$ \\
\hline-0.589 & null & R28285 & GC93180 & unknown & unknown $>$ \\
\hline-0.575 & null & $\mathrm{R} 07477$ & GC92891 & unknown & unknown \\
\hline-0.527 & null & AA747713 & GC49278 & unknown & unknown \\
\hline-0.526 & null & Al972104 & GC80541 & unknown & unknown \\
\hline-0.518 & null & Al382058 & GC64460 & unknown & unknown \\
\hline-0.505 & null & T95652 & GC95840 & $\begin{array}{l}\text { unknown } \\
\text { tuftelin interacting protein }\end{array}$ & unknown \\
\hline-0.504 & TFIP11 & AL080147 & GC164410 & $\begin{array}{l}11 \\
\text { IKAROS family zinc fingel }\end{array}$ & spliceosome disassembly; pre-mRNA splicing \\
\hline-0.503 & IKZF4 & Al261467 & GC61722 & $\begin{array}{l}4 \\
\text { potassium channel }\end{array}$ & Ikaros transcription factor family member \\
\hline-0.502 & KCTD15 & AA018217 & GC39879 & $\begin{array}{l}\text { tetrameri- } \\
\text { zation domain containing } \\
15\end{array}$ & unknown \\
\hline \multicolumn{6}{|l|}{$\begin{array}{l}\text { Vindoline: } \\
\text { Standard } \\
\text { COMPARE }\end{array}$} \\
\hline 0.745 & null & NM_016164 & GC186831 & & unknown \\
\hline 0.718 & null & Al688023 & GC70500 & & unknown \\
\hline 0.715 & ZNF414 & AW291109 & GC169427 & zinc finger protein 414 & transcriptional regulation \\
\hline 0.674 & FBXO21 & U79257 & GC191569 & F-box protein 21 & phosphorylation-dependent ubiquitination \\
\hline $\begin{array}{l}0.657 \\
0.652\end{array}$ & $\begin{array}{l}\text { RAB3B } \\
\text { HAS1 }\end{array}$ & $\begin{array}{l}\text { M28214 } \\
\text { NM_001523 }\end{array}$ & $\begin{array}{l}\text { GC32518 } \\
\text { GC181059 }\end{array}$ & $\begin{array}{l}\text { RAS family member } 3 B \\
\text { hyaluronan synthase } 1\end{array}$ & $\begin{array}{l}\text { vesicular protein transport (by similarity) } \\
\text { constituent of the extracellular matrix; }\end{array}$ \\
\hline 0.651 & KIAA1267 & AL042870 & GC82405 & KIAA1267 & $\begin{array}{l}\text { wound healing and tissue repair; tumor metastasis } \\
\text { unknown }\end{array}$ \\
\hline 0.643 & C19orf47 & BE297801 & GC172893 & $\begin{array}{l}3 \text { chromosome } 19 \text { open } \\
\text { reading frame } 47\end{array}$ & unknown \\
\hline 0.644 & null & M73255 & GC90241 & unknown & unknown \\
\hline $\begin{array}{l}0.637 \\
\text { Vindoline: } \\
\text { Reverse } \\
\text { COMPARE }\end{array}$ & null & M15205 & GC32801 & unknown & unknown \\
\hline-0.651 & null & AA894854 & GC51907 & unknown & unknown \\
\hline-0.636 & ZCWPW2 & Al677721 & GC69927 & $\begin{array}{l}\text { zinc finger, CW type } \\
\text { with PWWP domain } 2\end{array}$ & zinc-binding protein \\
\hline-0.633 & PSKH1 & W25248 & GC98337 & protein serine kinase $\mathrm{H} 1$ & $\begin{array}{l}\text { splicing factor compartment-associated serine } \\
\text { kinase } \\
\text { intranuclear SR-protein traffic, pre-mRNA } \\
\text { processing }\end{array}$ \\
\hline-0.631 & null & Al677570 & GC69940 & unknown & unknown \\
\hline-0.621 & null & Al668886 & GC69495 & $\begin{array}{l}\text { unknown } \\
\text { Rh-associated }\end{array}$ & unknown \\
\hline-0.612 & RHAG & Al052264 & GC57850 & glycoprotein & transports ammonium and carbon dioxide across \\
\hline
\end{tabular}




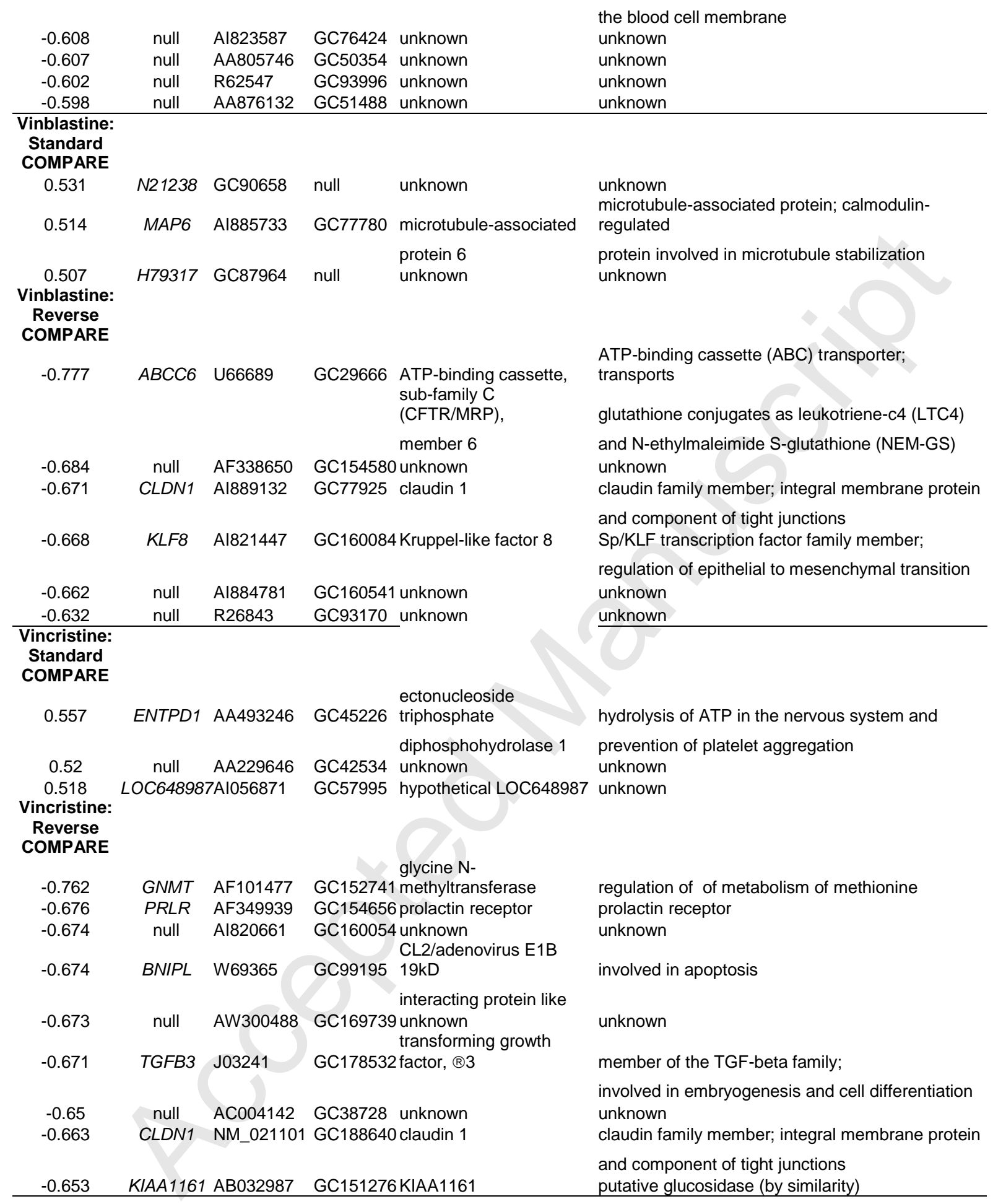

Information on gene functions was taken from the OMIM database, NCI, USA (http://www.ncbi.nlm.nih.gov/Omim/) and from the GeneCard database of the Weizman Institute of Science, Rehovot, Israel (http://bioinfo.weizmann.ac.il/cards/index.html). 
Table VI: Separation of clusters of the NCI cell line panel obtained by hierarchical cluster analysis shown in Figure 8 in comparison to Vinca alkaloids. The $\log _{10} \mathrm{IC}_{50}$ median values (M) of each compound were used as cut-off values to define cell lines as being sensitive or resistant. N.S., not significant $(P>0.05)$.

\begin{tabular}{llccccc} 
& & Partition & Cluster 1 & Cluster 2 & Cluster 3 & $\chi^{2}$ Test \\
\hline Catharanthine & sensitive & $<-4.358$ & 5 & 9 & 10 & \\
$(\mathrm{n}=48)$ & resistant & $>-4.358$ & 0 & 5 & 19 & $\mathrm{P}=0.01147$ \\
Vindoline & sensitive & $<-3.786$ & 9 & 1 & 14 & \\
$(\mathrm{n}=48)$ & resistant & $>-3.786$ & 0 & 11 & 13 & $\mathrm{P}=1.69 \times 10^{-4}$ \\
Vinblastine & sensitive & $<-9.130$ & 3 & 9 & 6 & \\
$(\mathrm{n}=58)$ & resistant & $>-9.130$ & 10 & 13 & 17 & N.S. \\
Vincristine & sensitive & $<-6.8955$ & 10 & 7 & 12 & \\
$(\mathrm{n}=58)$ & resistant & $>-6.8955$ & 5 & 3 & 21 & N.S. \\
\hline
\end{tabular}




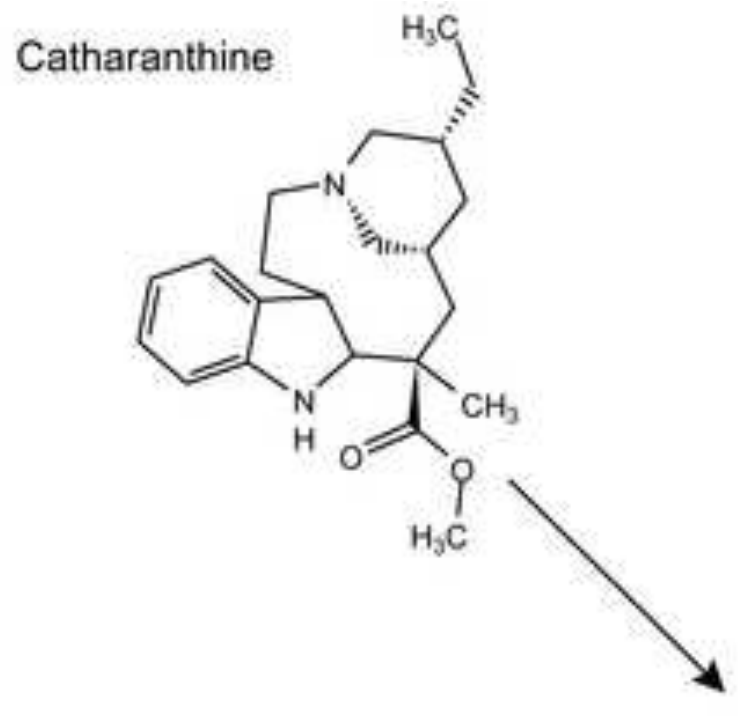

Vinblastine, $\mathrm{R}=\mathrm{CH}_{3}$ Vincristine, $\mathrm{R}=\mathrm{CHO}$

\section{Derivatives}

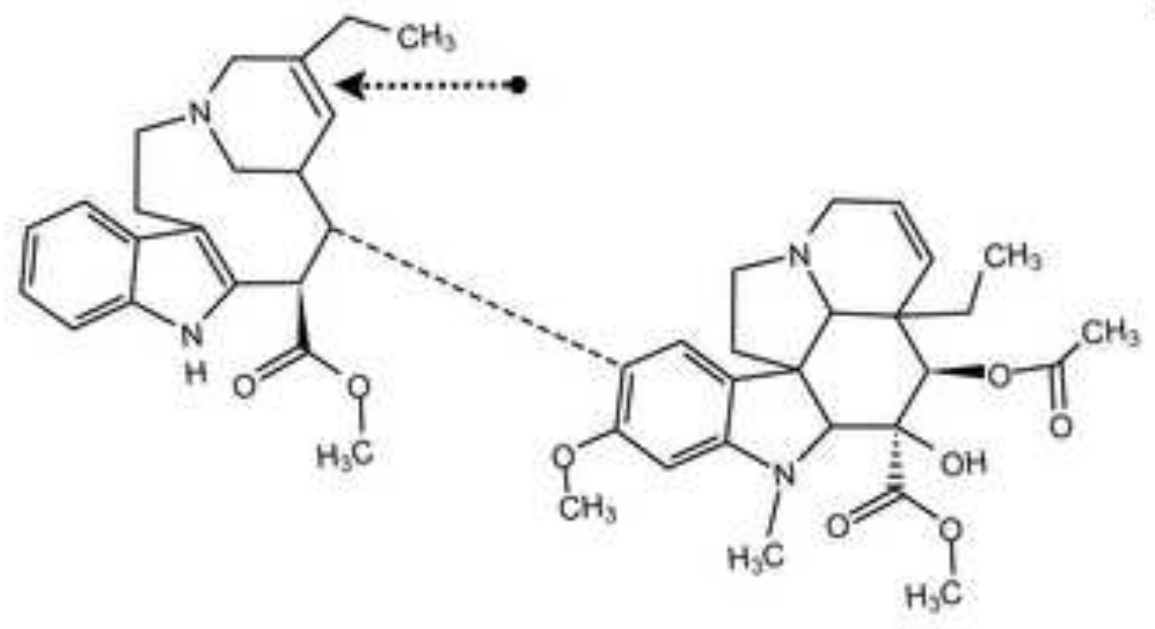

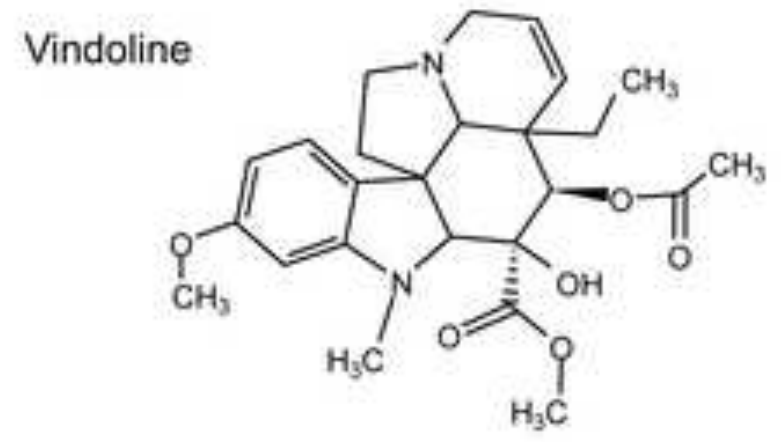<smiles>C=CC=CCCN1CCC(C)CC1</smiles>

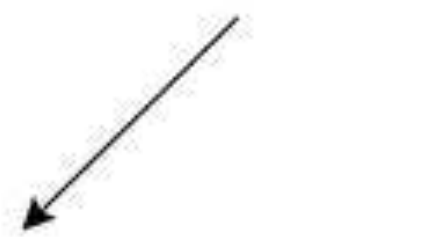

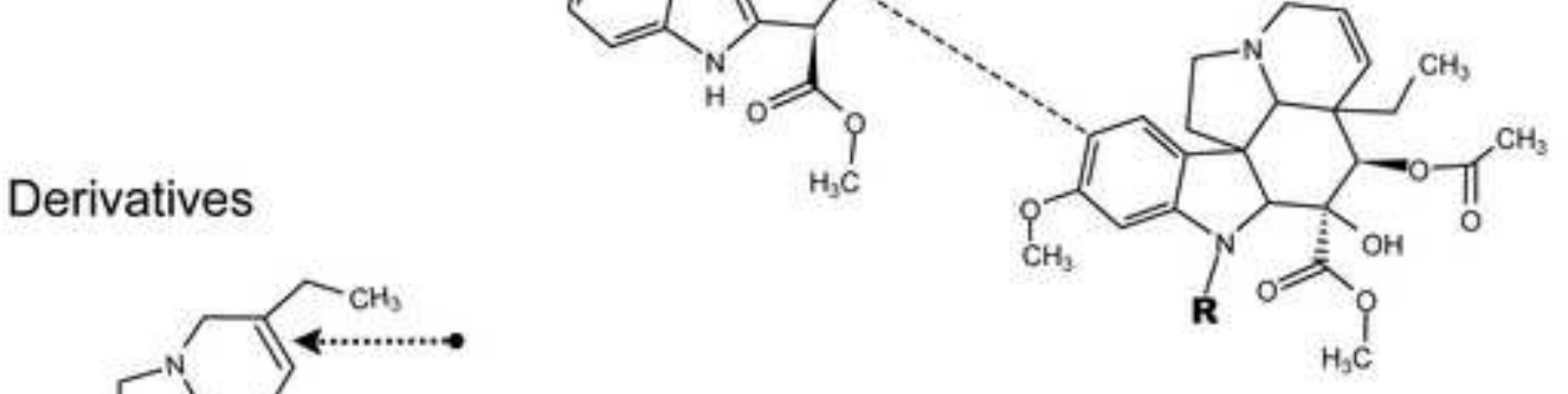

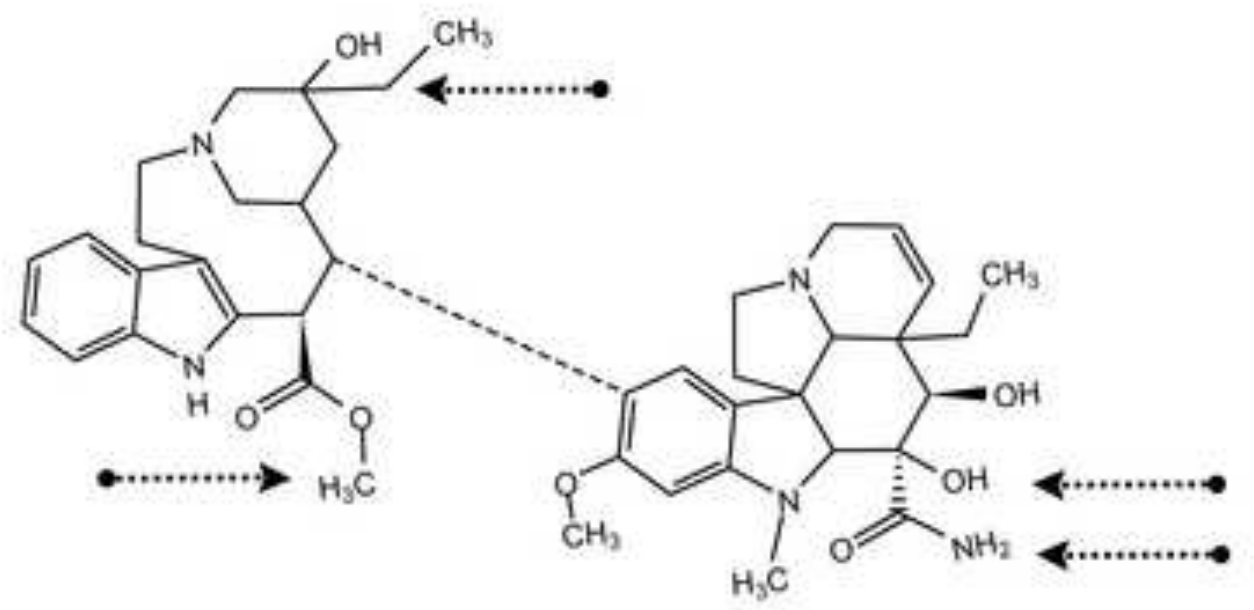

Vinorelbine

\section{Vindesine}




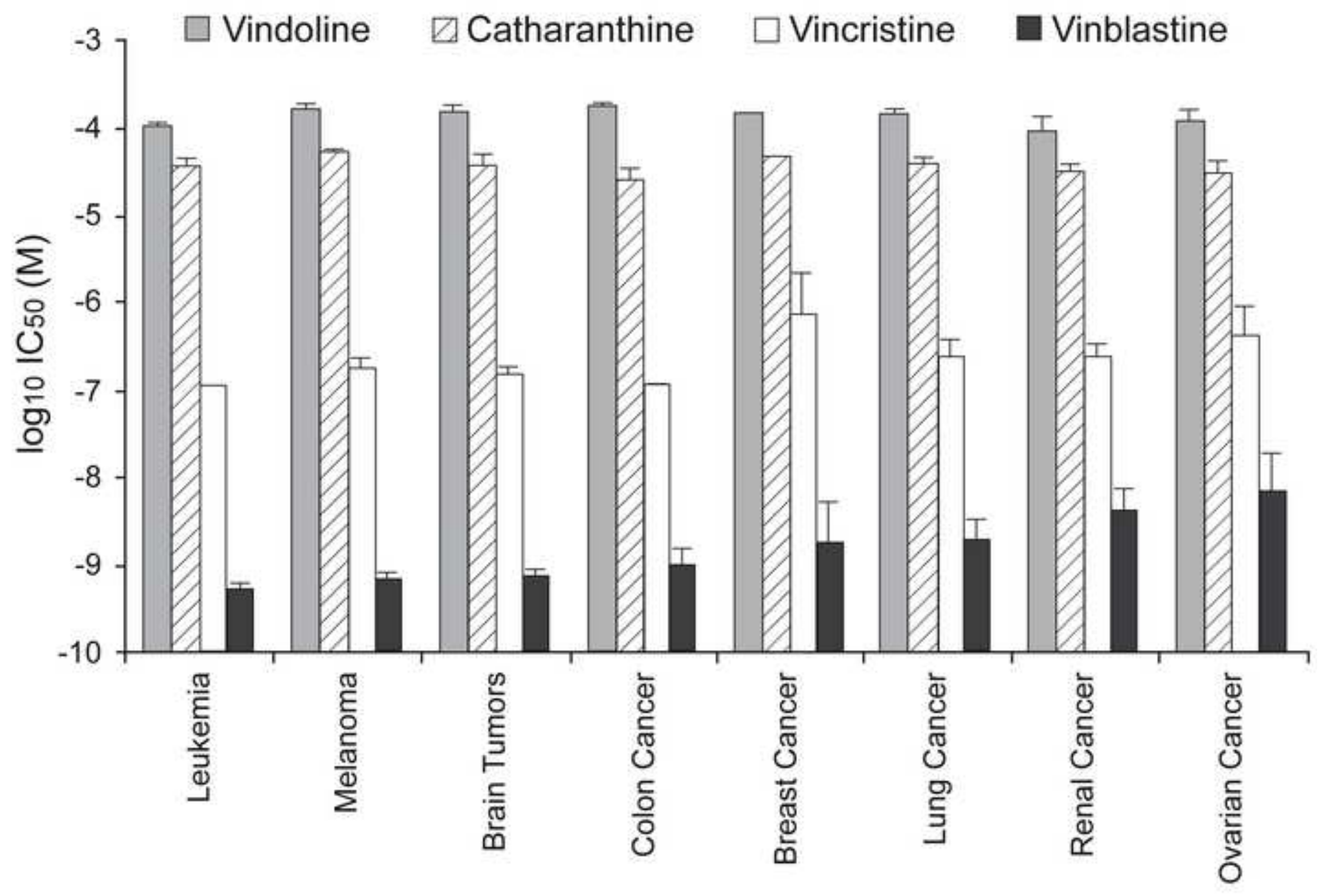




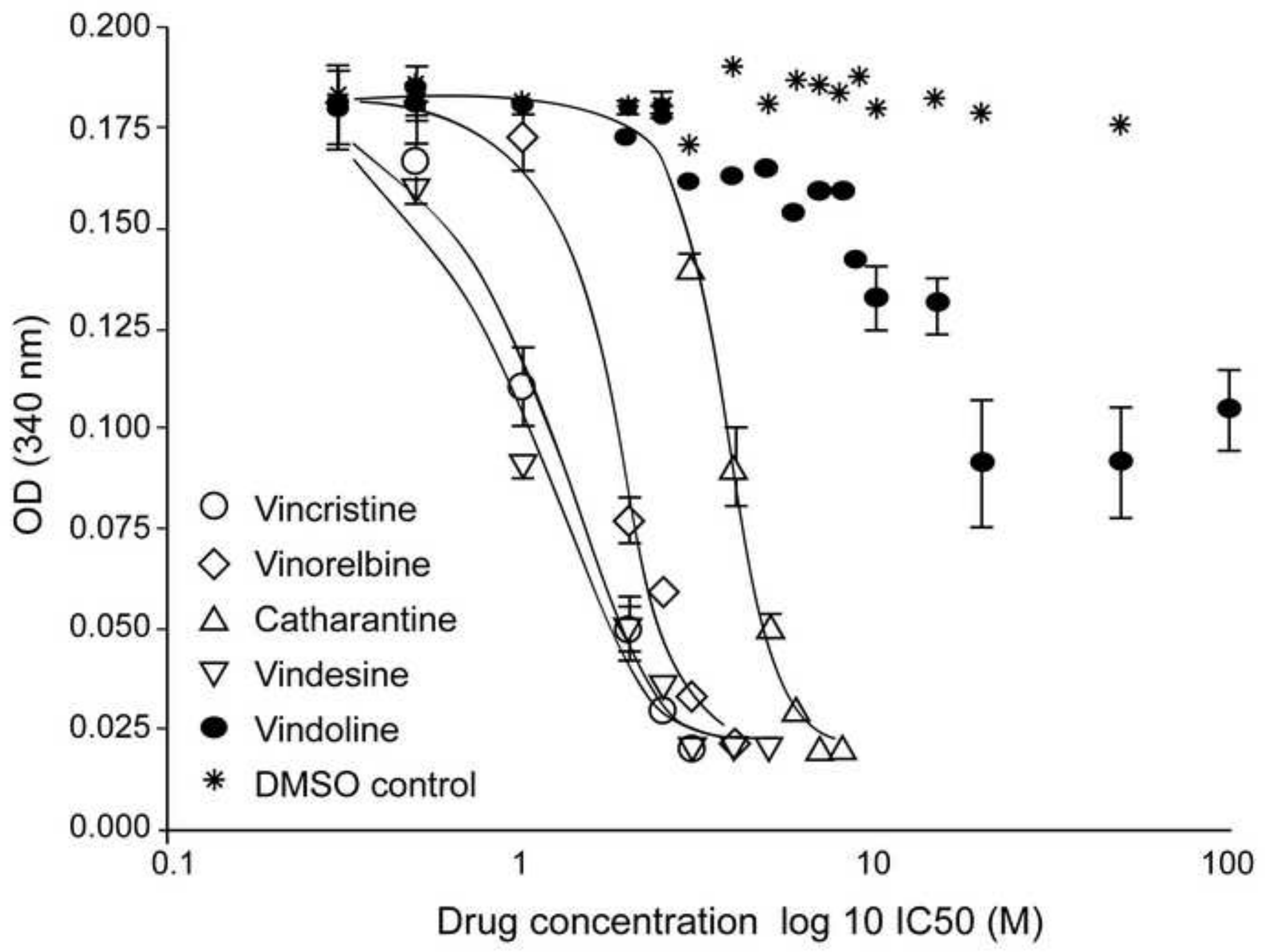




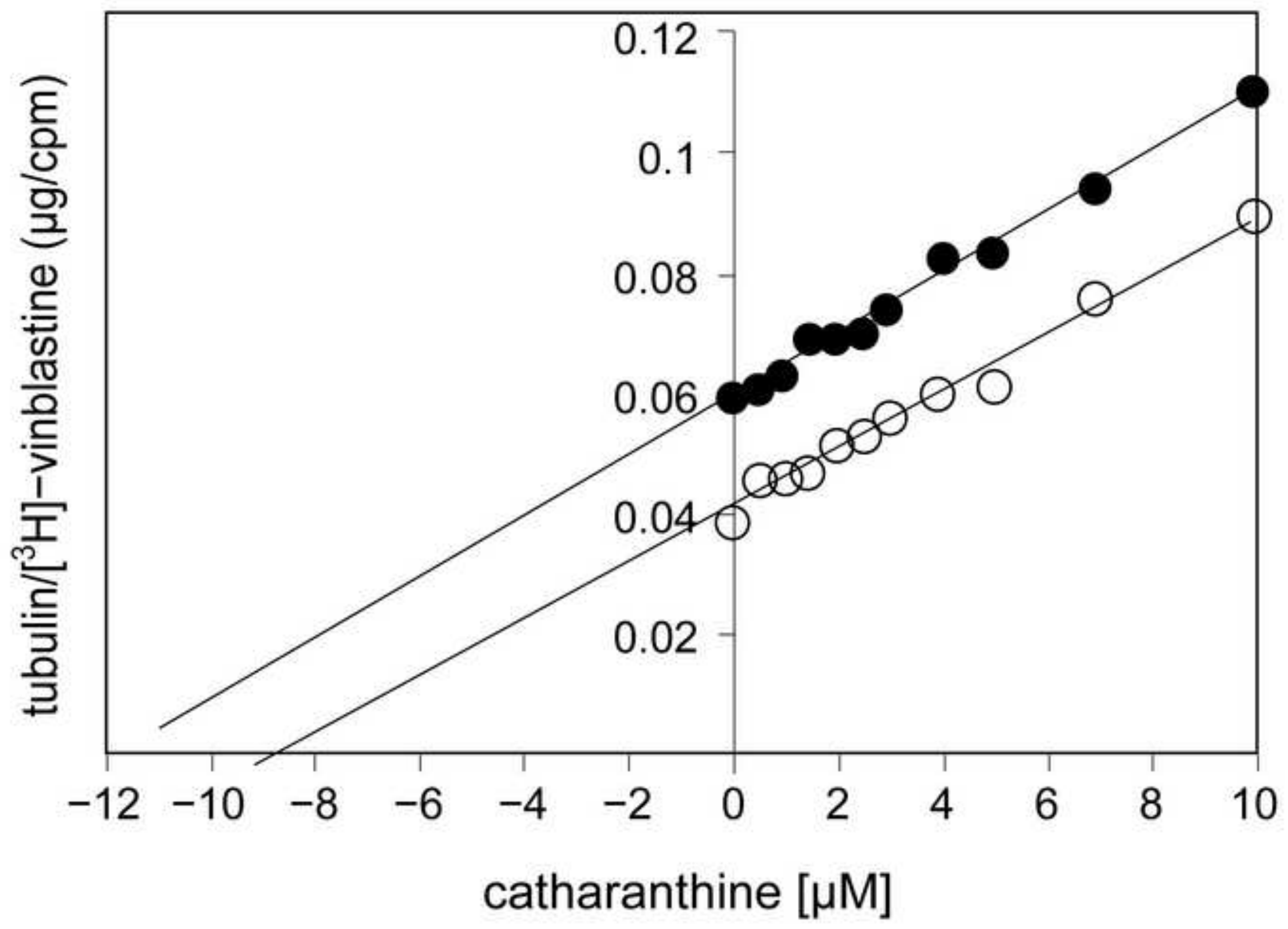

Page 36 of 42 
(A)
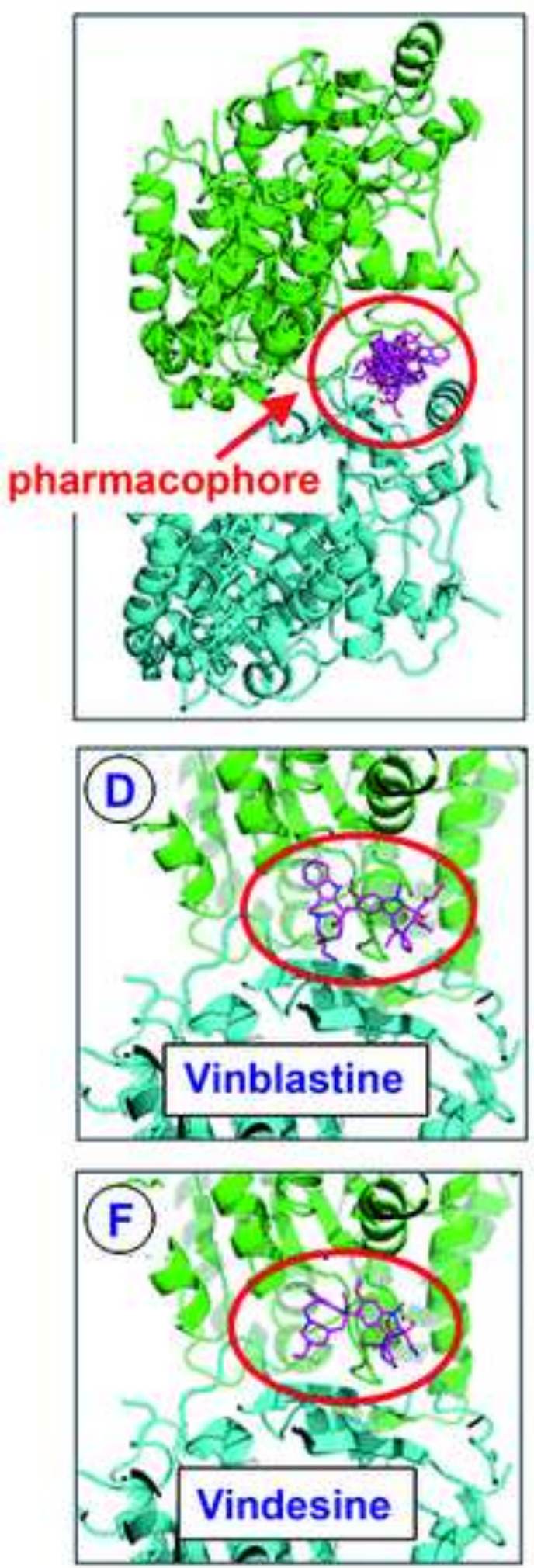
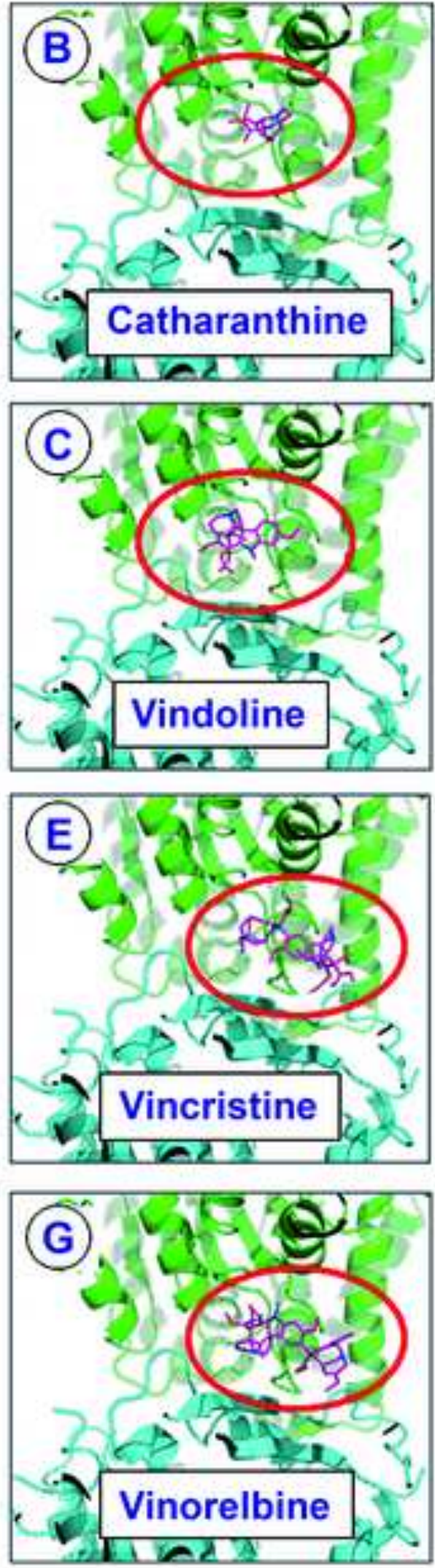


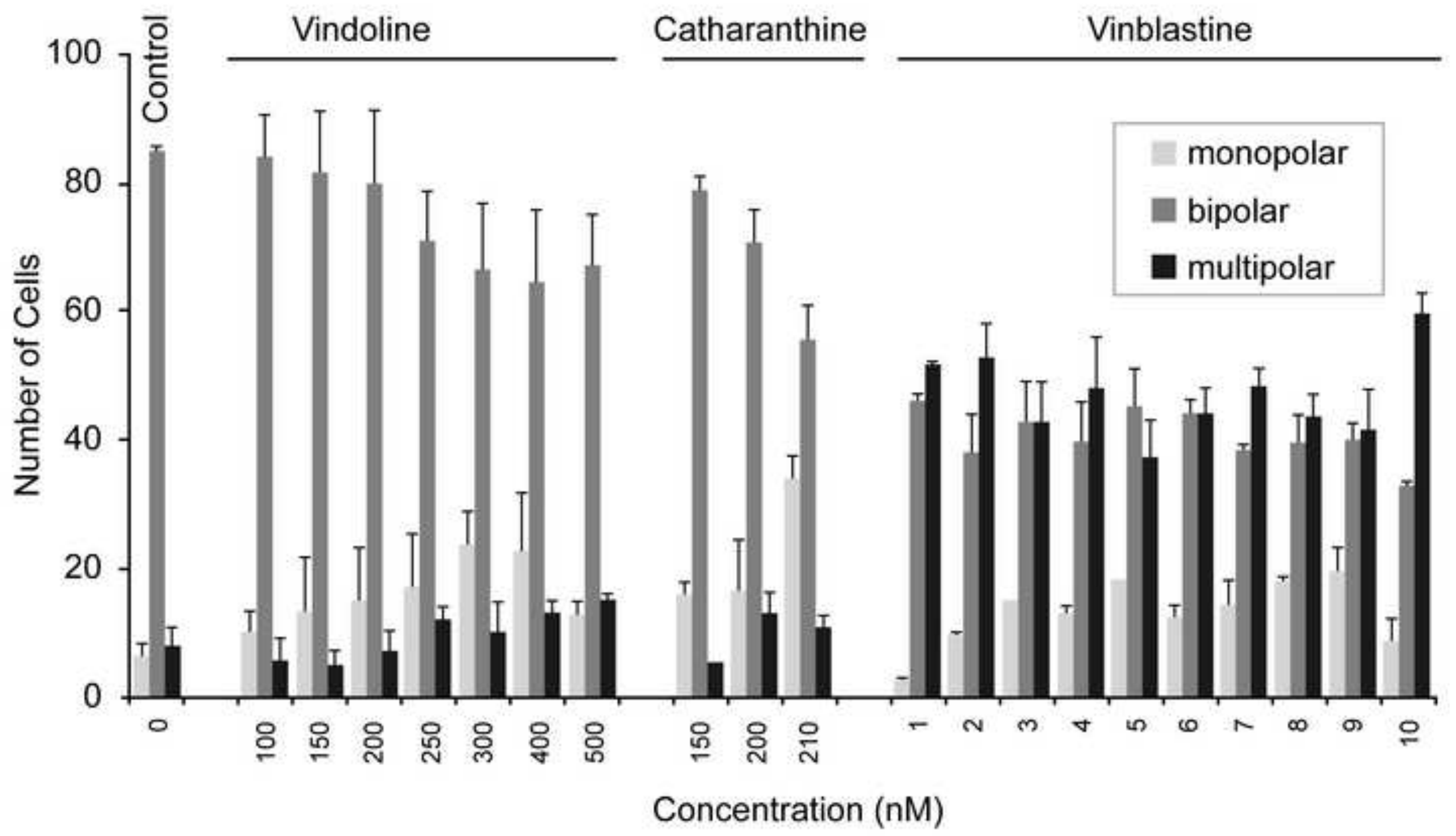



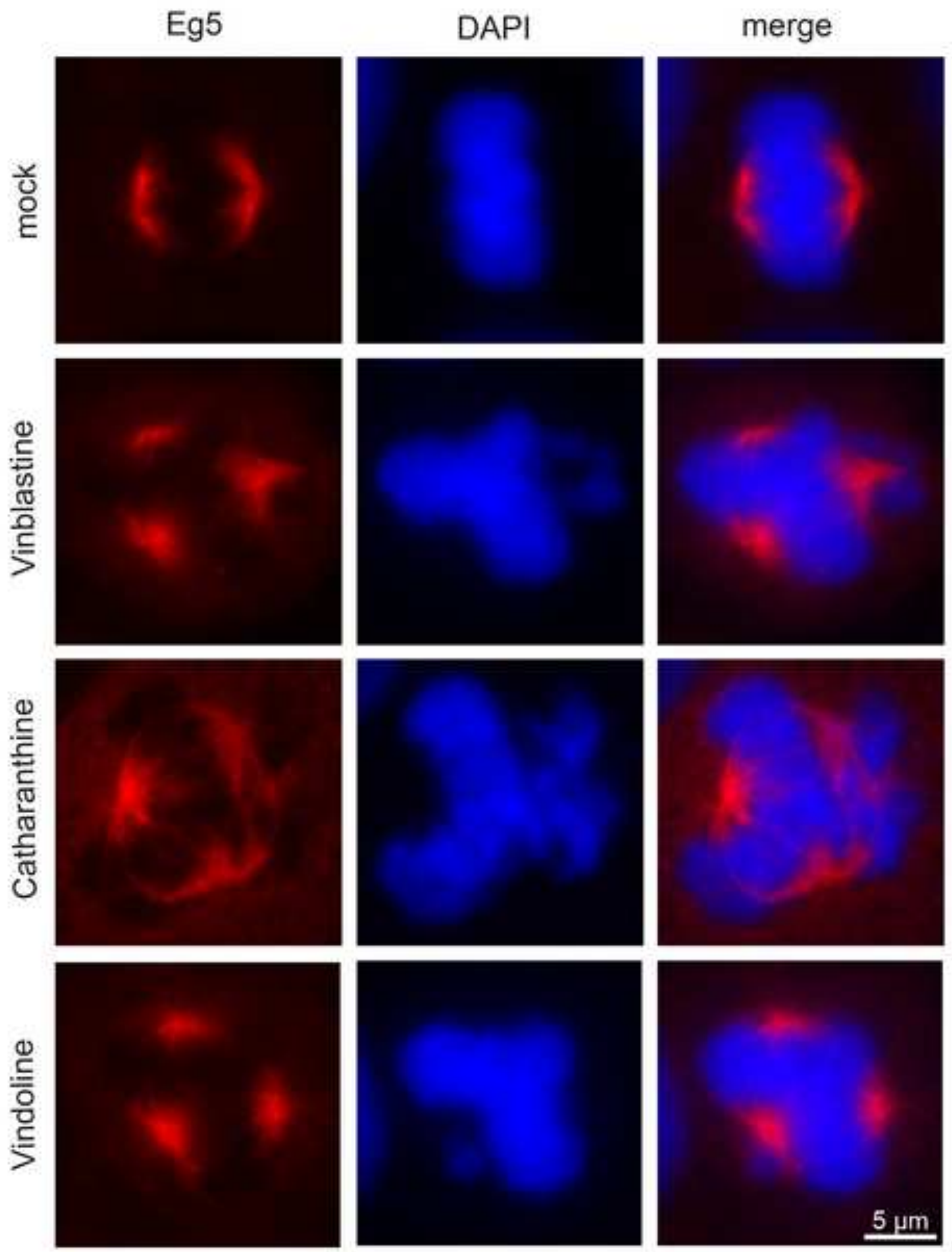

rage 39 of 42 


\section{$\begin{array}{ll}\text { A. Catharanthine } \quad \text { B. Vindoline } & \end{array}$}
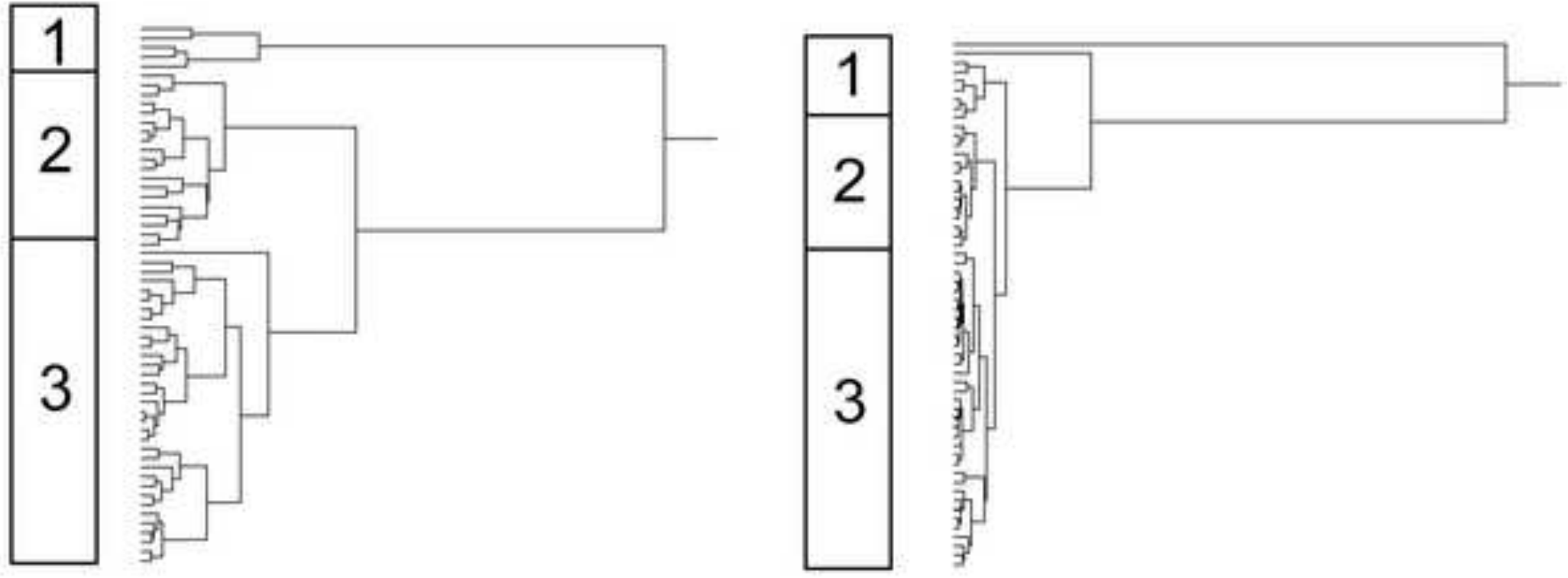

C. Vinblastine

D. Vincristine
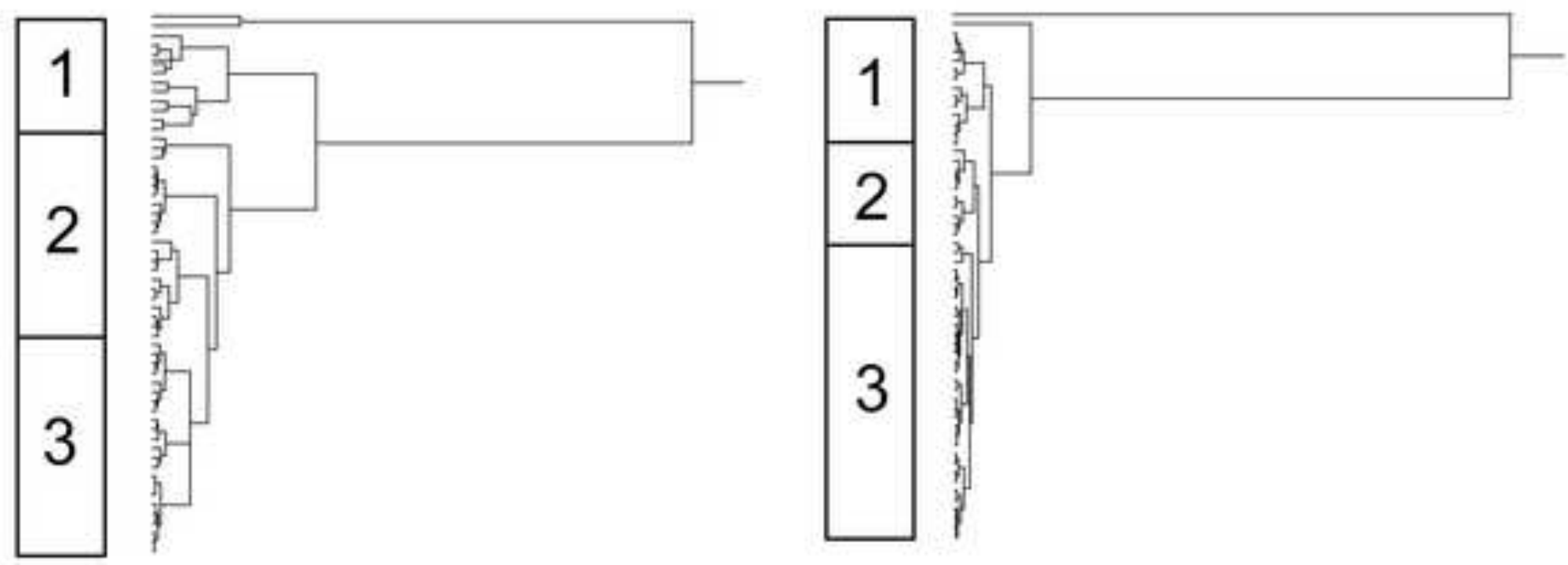
A.

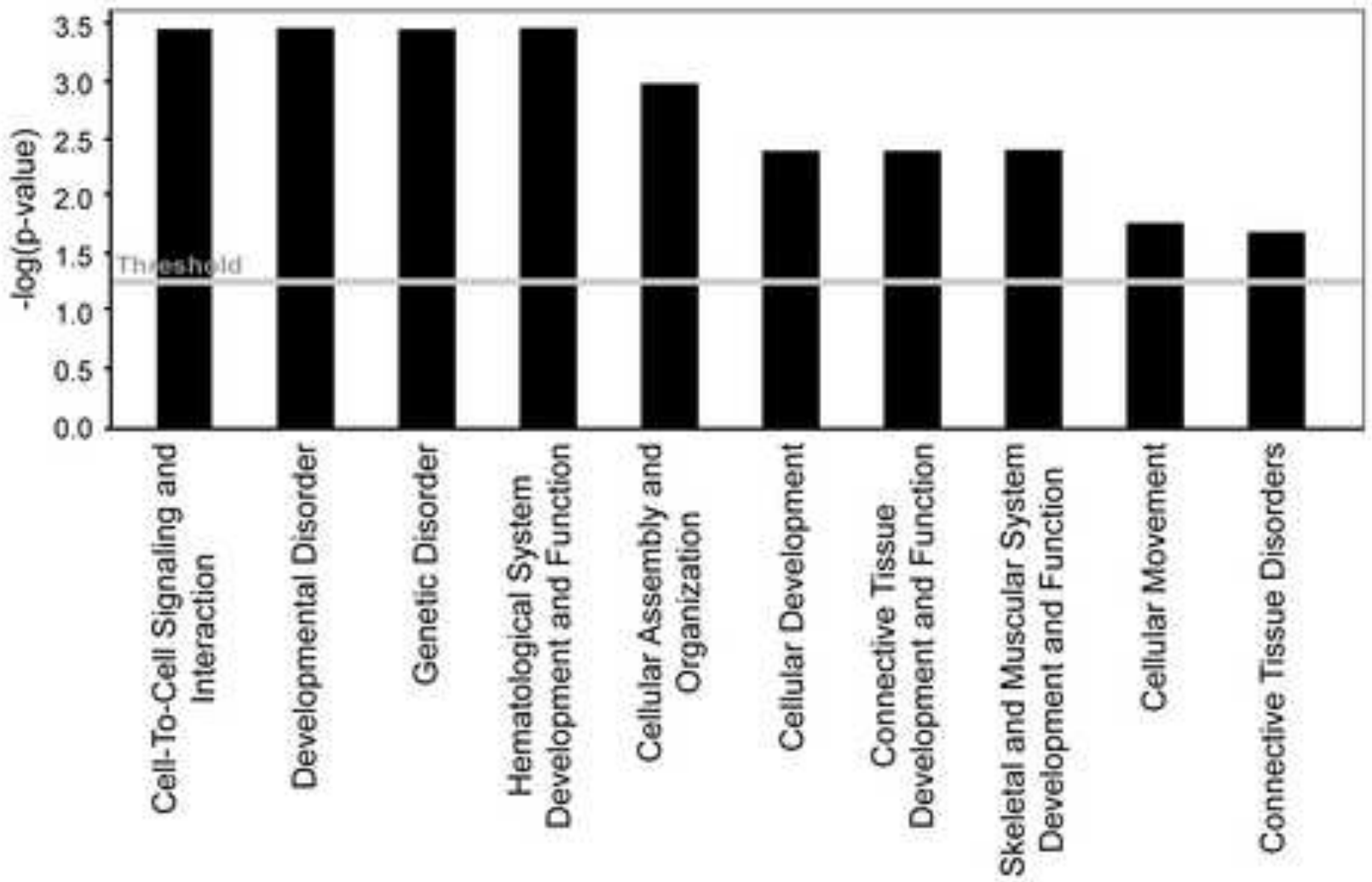

B.

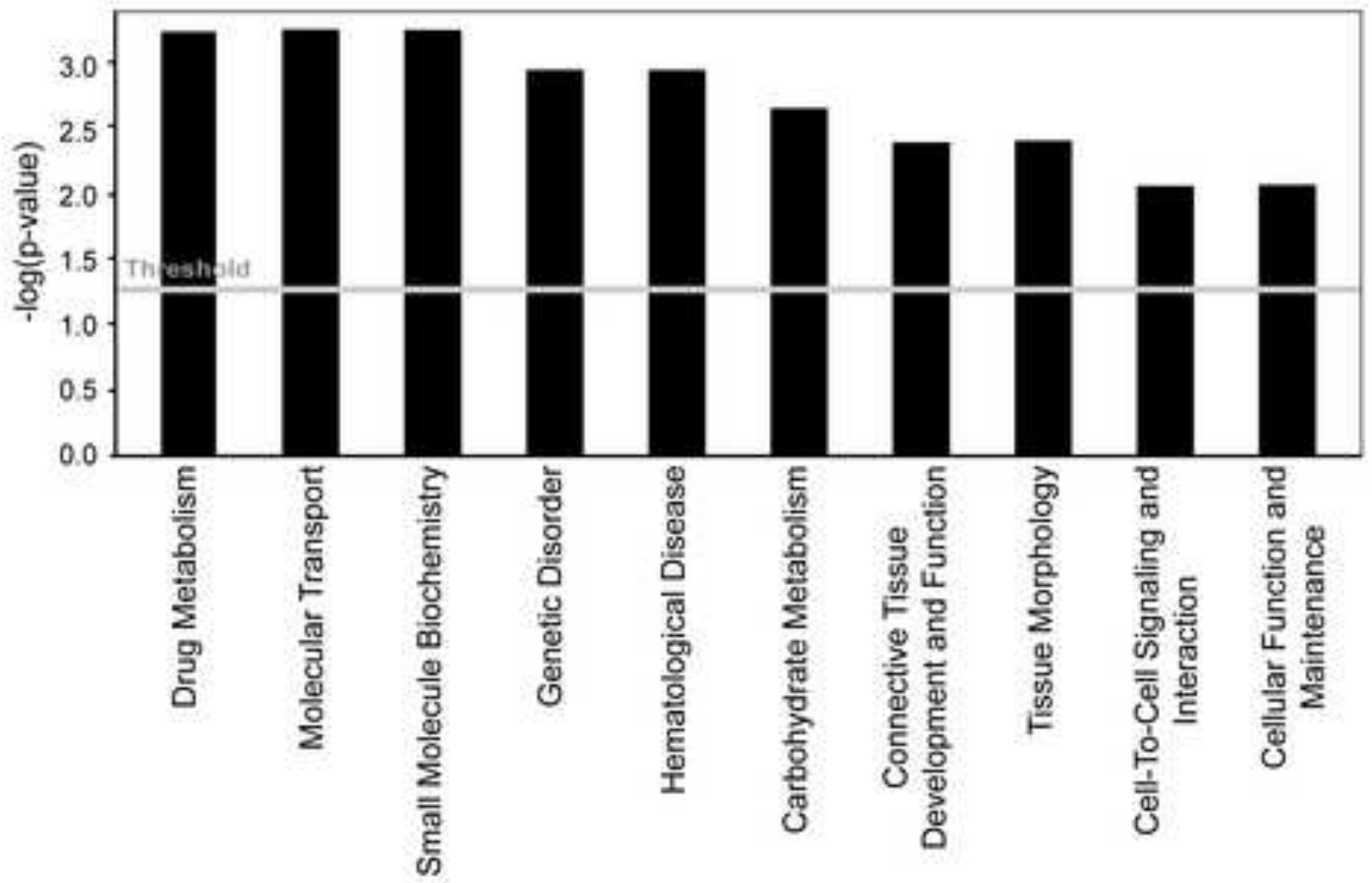




\section{Graphical Abstract}

Vinblastine produced high fractions of mono- and multipolar mitotic spindles, while its monomeric precursor molecules, vindoline and catharanthine did only weakly affect bipolar mitotic spindle formation. Inhibition of centrosomal clustering represents a novel strategy for cancer drug development and leads to the formation of multipolar spindles with subsequent apoptosis induction.
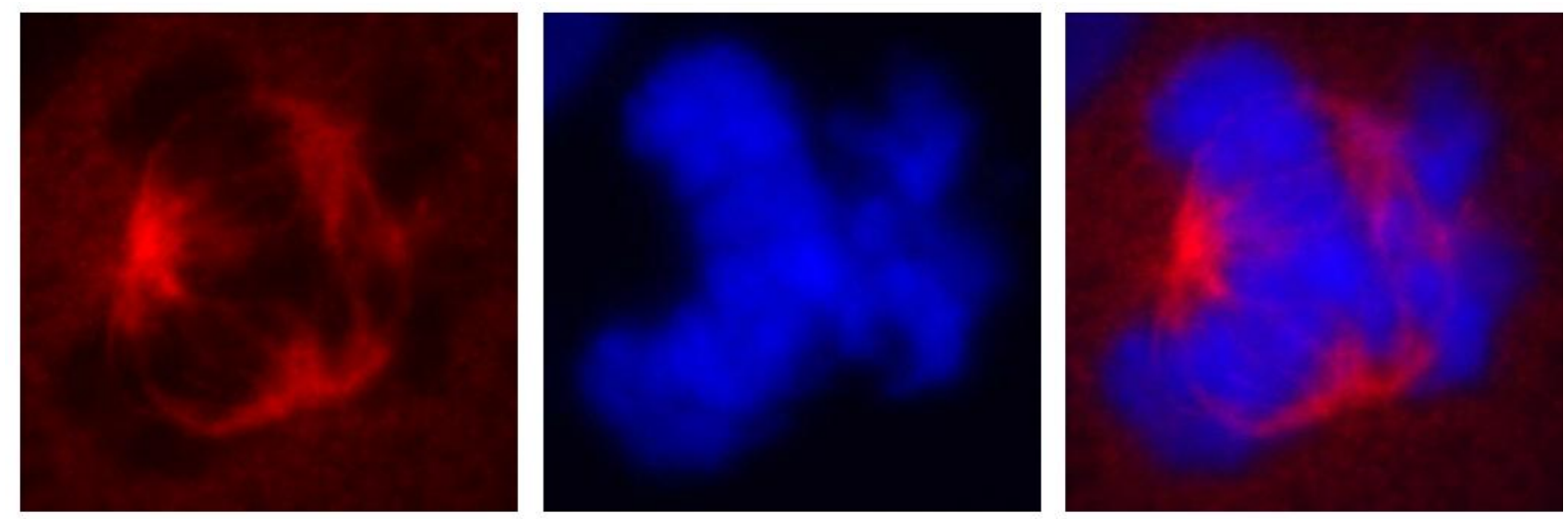